\title{
Descriptive anatomy of the largest known specimen of Protoichthyosaurus prostaxalis (Reptilia: Ichthyosauria) including computed tomography and digital reconstruction of a three-dimensional skull
}

\author{
Dean R. Lomax ${ }^{\text {Corresp.. }}{ }^{1}$ ， Laura B. Porro ${ }^{2}$ ， Nigel R. Larkin ${ }^{3}$ \\ ${ }^{1}$ School of Earth and Environmental Sciences, University of Manchester, Manchester, United Kingdom \\ 2 Department of Cell and Developmental Biology, University College London, London, United Kingdom \\ 3 Cambridge University Museum of Zoology, Cambridge, United Kingdom \\ Corresponding Author: Dean R. Lomax \\ Email address: dean.lomax@manchester.ac.uk
}

Ichthyosaur fossils are abundant in Lower Jurassic sediments with nine genera found in the UK. In this paper, we describe the partial skeleton of a large ichthyosaur from the Lower Jurassic (lower Sinemurian) of Warwickshire, England, which was conserved and rearticulated to form the centerpiece of a new permanent gallery at the Thinktank, Birmingham Science Museum in 2015. The unusual three-dimensional preservation of the specimen permitted computed tomography scanning of individual braincase elements as well as the entire reassembled skull. This represents one of the first times that medical imaging and three-dimensional reconstruction methods have been applied to a large skull of a marine reptile. Data from these scans provide new anatomical information, such as the presence of branching vascular canals within the premaxilla and dentary, and an undescribed dorsal (quadrate) wing of the pterygoid hidden within matrix. Scanning also revealed areas of the skull that had been modelled in wood, clay and other materials after the specimen's initial discovery, highlighting the utility of applying advanced imaging techniques to historical specimens. Additionally, the CT data served as the basis for a new three-dimensional reconstruction of the skull, in which minor damage was repaired and the preserved bones digitally rearticulated. Thus, for the first time a digital reconstruction of the skull and mandible of a large marine reptile skull is available. Museum records show the specimen was originally identified as an example of Ichthyosaurus communis but we identify this specimen as Protoichthyosaurus prostaxalis. The specimen features a skull nearly twice as long as any previously described specimen of $P$. prostaxalis, representing an individual with an estimated total body length between 3.2 and 4 meters. 
1 Descriptive anatomy of the largest known specimen of Protoichthyosaurus prostaxalis

2 (Reptilia: Ichthyosauria) including computed tomography and digital reconstruction of a

3 three-dimensional skull

5 Dean R. Lomax ${ }^{1}$, Laura B. Porro ${ }^{2}$, Nigel R. Larkin ${ }^{3}$

$6{ }^{1}$ School of Earth and Environmental Sciences, The University of Manchester, Oxford Rd,

7 Manchester, M13 9PL, United Kingdom

$8{ }^{2}$ Department of Cell and Developmental Biology, University College London, WC1E 6BT,

$9 \quad$ United Kingdom

$10{ }^{3}$ Cambridge University Museum of Zoology, Downing St, Cambridge, CB2 3EJ, United

11 Kingdom

13 Corresponding Author: Dean R. Lomax, dean.lomax@manchester.ac.uk

\section{Abstract}

Ichthyosaur fossils are abundant in Lower Jurassic sediments with nine genera found in the UK.

17 In this paper, we describe the partial skeleton of a large ichthyosaur from the Lower Jurassic

18 (lower Sinemurian) of Warwickshire, England, which was conserved and rearticulated to form

19 the centerpiece of a new permanent gallery at the Thinktank, Birmingham Science Museum in 2015. The unusual three-dimensional preservation of the specimen permitted computed

21 tomography scanning of individual braincase elements as well as the entire reassembled skull.

22 This represents one of the first times that medical imaging and three-dimensional reconstruction

23 methods have been applied to a large skull of a marine reptile. Data from these scans provide 
24

25

26

27

28

new anatomical information, such as the presence of branching vascular canals within the premaxilla and dentary, and an undescribed dorsal (quadrate) wing of the pterygoid hidden within matrix. Scanning also revealed areas of the skull that had been modelled in wood, clay and other materials after the specimen's initial discovery, highlighting the utility of applying advanced imaging techniques to historical specimens. Additionally, the CT data served as the basis for a new three-dimensional reconstruction of the skull, in which minor damage was repaired and the preserved bones digitally rearticulated. Thus, for the first time a digital reconstruction of the skull and mandible of a large marine reptile skull is available. Museum records show the specimen was originally identified as an example of Ichthyosaurus communis but we identify this specimen as Protoichthyosaurus prostaxalis. The specimen features a skull nearly twice as long as any previously described specimen of $P$. prostaxalis, representing an individual with an estimated total body length between 3.2 and 4 meters.

\section{Introduction}

Ichthyosaurs were a highly successful group of predatory marine reptiles that appeared in the late Early Triassic and went extinct in the early Late Cretaceous (Fischer et al., 2016). Some of the earliest forms were 'lizard-like' in appearance, although later forms evolved fish-shaped bodies (Motani, 2009). Species ranged in size from small-bodied forms less than $1 \mathrm{~m}$ long to giants over $20 \mathrm{~m}$ in length (Motani, 2005; Nicholls \& Manabe, 2004; Lomax et al., 2018). Numerous Lower Jurassic ichthyosaurs have been found in the UK, the majority being from the Lyme RegisCharmouth area in west Dorset (Milner \& Walsh, 2010), the village of Street and surrounding areas in Somerset (Delair, 1969), sites around the coastal town of Whitby, Yorkshire (Benton \& Taylor, 1984) and Barrow-upon-Soar, Leicestershire (Martin et al., 1986). Notable specimens 
47 have also been recorded from Ilminster, Somerset (Williams et al., 2015), Nottinghamshire

48 (Lomax \& Gibson, 2015) and Warwickshire (Smith \& Radley, 2007), with various isolated

49

50

51

52

53

54

55

56

57

58

occurrences at other sites across the UK (Benton \& Spencer, 1995).

A partial ichthyosaur skeleton (BMT 1955.G35.1 - Birmingham Museums Trust) was

discovered in 1955 in Warwickshire, England. The specimen comprises a largely complete skull, portions of the pectoral girdle, pelvis, fore- and hindfins, and numerous vertebrae and ribs. Bones of the basicranium and palate were also found, which are rarely observed in association with Lower Jurassic ichthyosaur skulls (Marek et al., 2015). The skull bones were reassembled threedimensionally on a wood and metal frame held together with alvar, jute and kaolin dough, with missing parts carved from wood; however, some aspects were not accurately reconstructed.

Museum records indicate that BMT 1955.G35.1, which has never been formally described, was originally identified as an example of Ichthyosaurus communis De la Beche \& Conybeare 1821. In 2015, as part of the development of the new Marine Worlds Gallery at the Thinktank, Birmingham Science Museum, the skull was dismantled, conserved and reassembled to be more anatomically accurate. The skull and postcranial skeleton of BMT 1955.G35.1 were publicly displayed for the first time, forming the centerpiece of this permanent gallery. The skull of BMT 1955.G35.1 is preserved in 3D and is free of matrix; this contrasts with the majority of Lower Jurassic ichthyosaur skulls, which are often flattened or displaced and preserved in matrix, enabling a more detailed description than is typical. The large size of many marine reptile skulls has precluded attempts to visualize specimens using medical imaging (but see McGowan, 1989). Given the exceptional 3D preservation, the fact it is relatively free of matrix, and access to facilities capable of imaging large specimens, we took the opportunity to scan individual cranial elements as well as the entire skull of BMT 1955.G35.1 using computed tomography (CT) 
70 before and after reassembly. Computed tomography and 3D digital reconstruction are

71 increasingly being applied to the skulls of fossil vertebrates, including early tetrapods (Porro et

72 al., 2015a,b), dinosaurs (Rayfield et al., 2001; Lautenschlager et al., 2014, 2016; Porro et al.,

73 2015c; Button et al., 2016) and extinct synapsids (Wroe, 2007; Jasinoski et al., 2009; Sharp,

74 2014; Cox et al., 2015; Lautenschlager et al., 2017). The first attempt to understand the internal

75 anatomy of the ichthyosaur skull was carried out by Sollas (1916) using serial grinding; although

76 this method produced excellent understanding of skull anatomy, it was time-consuming, labour

77 intensive and resulted in the destruction of the specimen. In contrast, modern medical imaging

78 methods have been applied only to isolated regions of fossil marine reptile skulls (Kear, 2005;

79 Fernández et al., 2011; Sato et al., 2011; Neenan and Scheyer, 2012; Herrera et al., 2013), with

80 the exception of one pliosaur (Foffa et al., 2014a), one small ichthyosaur (Marek et al., 2015), for

81 which entire skulls were CT scanned, and the skeleton of a juvenile plesiosaur (Larkin et al.,

82 2010).

In this paper, we use CT scanning of a large ichthyosaur skull along with careful

84

\section{Geological setting}


92 BMT 1955.G35.1 was collected in situ from Fell Mill Farm, between Shipston-on-Stour and

93 Honington, Warwickshire, England, grid reference NGR SP 277 415. The initial discovery was

94 made by Mr Michael Bryan in May, 1955. A complete excavation, under the supervision of

95 Assistant Keeper of Natural History at the City of Birmingham Museum, Mr Vincent Smith,

96 subsequently took place. The specimen was found approximately 4 feet below the ground surface

97 in a hard, blue-grey clay, lying directly on top of a brown grit layer containing numerous

98 Gryphaea bivalves. Due to the fragmentary nature of the bones, they were removed embedded in 99 clay.

100 Precise stratigraphic data associated with the discovery are not available but the remains

101 were recorded as being from Liassic sediments, which conforms to the Early Jurassic age of the

102 region's geology (Edmonds et al., 1965; Radley, 2003; Smith \& Radley, 2007). In addition to the

103 ichthyosaur skeleton, other fossils were collected alongside the specimen, including Gryphaea

104 bivalves, a plesiosaur vertebra, and an isolated shark tooth identified as Hybodus cf. H. cloacinus

105 Quenstedt 1858, which are also Early Jurassic in age, although this shark species ranges from the

106 Rhaetic through Lower Lias (N. R. Larkin, pers. comm. D. Ward, 2015). Additionally, we found

107 an ammonite fragment stored with the specimen, which is an example of Euagassiceras

108 sauzeanum (d'Orbigny 1844), a species indicative of the Semicostatum Ammonite Zone, lower

109 Sinemurian, Lower Jurassic (DRL pers. comm. M. Howarth, 2017). As there was no record

110 stating whether this ammonite fragment was physically collected with BMT 1955.G35.1, NRL

111 was given permission by the current owners of Fell Mill Farm to collect other fossils along with

112 matrix from the original site at a depth of $2 \mathrm{~m}$ below the surface. This resulted in the collection

113 of numerous ammonites identified as Arnioceras semicostatum (Young \& Bird 1828), which is

114 also indicative of the lower Sinemurian, Semicostatum Ammonite Zone (DRL pers. comm. M. 
115 Howarth, 2017). Thus, associated ammonites have provided the stratigraphic position of BMT 116 1955.G35.1.

117

\section{Material and methods}

119

120

121

122

123

124

125

126

127

128

129

130

131

132

133

134

135

136

137

BMT 1955.G35.1 is currently housed in the Thinktank Science Museum (TSM). It was originally accessioned into the collections of Birmingham Museum and Art Gallery (BMAG) and loaned to TSM. However, BMAG and TSM have since become part of the Birmingham Museums Trust (BMT). The postcranial skeleton, long considered 'missing', was rediscovered in the collections of the Lapworth Museum of Geology (BU) and reunited with the skull as part of a funded project at the TSM. As BMT 1955.G35.1 was largely undeformed, the individual skull bones were assembled in 3D; however, several errors were made in this original reconstruction (Fig. 1A). As part of the funded project, the skull was disassembled and the individual bones cleaned, conserved, and remounted (Fig. 1B-C). Many of the preserved skull bones were disarticulated when discovered and several cranial bones are not represented. The teeth have been reset and are not in their original positions. Portions of some elements are poorly preserved and/or taphonomically distorted, which somewhat restricts our description; for example, the dentaries cannot be articulated at the symphysis or mounted in their correct anatomical position. The newly reassembled skull of BMT 1955.G35.1 is based on all the preserved elements robust enough to safely include, and we limit our description of sutural contacts to those between elements preserved in original articulation. Specific details of the reconstruction and conservation of the studied specimen will be dealt with in a separate paper.

Prior to remounting, several individual bones of the left side of the skull were scanned using microcomputed tomography $(\mu \mathrm{CT})$ in March 2015 at the Cambridge Biotomography 
138 Centre (Zoology Department, University of Cambridge) on an X-Tek H $225 \mu$ CT scanner (Nikon

139 Metrology, Tring, UK) at $135 \mathrm{kV}$ and $227 \mu \mathrm{A}$ with no filtering. Elements scanned individually

140 include: the left articular, opisthotic, stapes, quadrate and pterygoid; the median supraoccipital

141 and basisphenoid; and both parietals. Voltage, current and resolution $(0.1 \mathrm{~mm} /$ voxel $)$ were

142 identical for all scans. Scan data were visualized in the software Avizo 8.0 (Thermo Fisher

143 Scientific, Waltham, Massachusetts, USA) and the left-side elements mirrored across the sagittal

144 midline. All 3D surfaces were exported as stereolithography (STL) files and 3D printed at life-

145 size in gypsum on a 3DS x60 3D Printer; pieces were subsequently dipped in cyanoacrylate for

146 strength (NRL pers. comm. S. Dey, 2016).

After remounting, the skull of BMT 1955.G35.1, including the 3D printouts previously

148 described, was scanned in May 2015 at the Royal Veterinary College on a Lightspeed Pro 16 CT

149 scanner (GE Medical Systems LTd., Pollards Wood, UK) at $120 \mathrm{kV}$ and $200 \mu \mathrm{A}$. Due to the size

150 of the specimen, it was scanned in two parts - the front of the skull was scanned at

$1510.56 \times 0.56 \times 1.25 \mathrm{~mm} /$ voxel and the rear of the skull was scanned at $0.73 \times 0.73 \times 1.25 \mathrm{~mm} /$ voxel.

152 Both scans produced a total of 2168 DICOM slices. Both scans used an exposure time of 2356

153 ms and a body filter. Density thresholding was used to separate higher-density fossil bone from

154 lower-density matrix as well as areas of the skull historically modelled in wood, clay and jute,

155 and portions newly modelled in gypsum. Scans were segmented to isolate individual bones and

156 teeth, and to trace internal features. The two halves of the skull were overlain and merged using

157 skeletal landmarks visible in both datasets (Figs. 2-4). Three-dimensional surfaces were exported 158 as wavefront (OBJ) files to create an interactive 3D PDF using Tetra4D Reviewer and Converter

159 (Tech Soft 3D; Oregon, USA) and Adobe Acrobat Pro X (Adobe Systems, California, USA). 
160 This reconstruction is provided as supporting information (Appendix S1) and are the basis for the

161 following description.

162 Surface models of individual bones were manipulated in 3D space using the Transform

163 Editor within Avizo, allowing digital 3D reconstruction of the skull of BMT 1955.G35.1

164 following similar methods applied to early tetrapods (Porro et al. 2015a,b) and dinosaurs

165 (Lautenschlager, 2016). Most of the bones in the digital reconstruction are from the left side of

166 BMT 1955.G35.1 as this side is generally better preserved. Minor damage was manually repaired

167 in the Segmentation Editor within Avizo using interpolation, including: minor breaks and

168 missing alveolar margins in the left premaxilla, maxilla, dentary and splenial; minor breaks in the

169 left nasal, lacrimal, jugal, quadrate, pterygoid, and parietal; the missing right margin of the

170 supraoccipital; and gaps within the anterior half of the left surangular. Portions of bones

171 preserved on the right but absent on the left - including the posterior tip of the right jugal and

172 anterior tip of the right splenial - were duplicated, reflected across the sagittal midline, and

173 merged with left side elements using anatomical landmarks. We did not attempt to reconstruct

174 missing bones or preserved elements that could not be scanned due to their delicate nature (see

175 Results). The disarticulated bones were then fitted together at sutural contacts; we also referred

176 to known relationships between skull bones from other ichthyosaur skulls (Andrews, 1910;

177 Sollas, 1916; McGowan, 1973; Kirton, 1983; McGowan \& Motani, 2003; Marek et al., 2015;

178 Moon \& Kirton, 2016). Lastly, left side elements were duplicated and reflected to form the right

179 side of the skull. Transformation matrices for all bones from the original data set to the final 3D

180 reconstruction are available as supporting information (Appendix S2); a 3D PDF of the

181 reconstructed skull is also available as supporting information (Appendix S3). 


\section{Institutional abbreviations}

184 BMT, Birmingham Museums Trust (encompasses BMAG, Birmingham Museum and Art

185 Gallery and TSM, Thinktank, Birmingham Science Museum), UK; BRLSI, Bath Royal Literary

186 and Scientific Institution, Bath, UK; BU, Lapworth Museum of Geology, University of

187 Birmingham, UK; LEICT, Leicester Arts and Museums Service, New Walk Museum and Art

188 Gallery, Leicester, UK; NHMUK, Natural History Museum, London, UK; SOMAG (formerly

189 AGC), Alfred Gillett Collection, cared for by the Alfred Gillett Trust (C \& J Clark Ltd), Street,

190 Somerset, UK; UNM, University of Nottingham Museum, UK.

191

192 Systematic Palaeontology

193 Ichthyosauria de Blainville, 1835

194 Parvipelvia Motani, 1999

195 Ichthyosauridae Bonaparte, 1841

196 Protoichthyosaurus Appleby, 1979

197 Protoichthyosaurus prostaxalis Appleby, 1979

198

199 Type species. P. prostaxalis Appleby 1979. The type series of specimens are from historic

200 collections. However, the holotype is most likely from the area around Street, Somerset and is

201 most likely from the lowermost Jurassic (lower Hettangian) 'Pre-Planorbis Beds' (i.e., Tilmanni

202 Ammonite Zone) of the Blue Lias Formation, although it could be latest Triassic (Rhaetian). See

203 Lomax et al., (2017) for more details. 
205 206 view.

207

208

209

210

211

212

213

214

215

216

217

218

219

220

221

222

223

224

225

226

227

Holotype. BRLSI M3553, a partial skull, pectoral girdle, and both forefins, preserved in ventral

Paratypes. BRLSI M3555, a skull and partial skeleton, preserved in right lateral view; BRLSI

M3563, a composite partial skeleton; LEICT G454.1951/164, a partial forefin, presently missing, which might be a hindfin of a different genus (see Lomax, Massare \& Mistry, 2017 for more details).

Referred specimen. BMT 1955.G35.1, an almost complete, three-dimensional skull and partial postcranial skeleton.

Emended diagnosis. As in Lomax et al., (2017), but with the following change: total length greater than $3.2 \mathrm{~m}$ but probably less than $4 \mathrm{~m}$.

Occurrence. Fell Mill Farm, between Shipston-on-Stour and Honington, Warwickshire, England, grid reference NGR SP 277 415. The specimen was collected from blue-grey Liassic clay, and specifically from the Semicostatum Ammonite Zone, lower Sinemurian, Lower Jurassic.

\section{Results}

Anatomical description of the skull roof

Measurements of the skull are presented in Table 1. In lateral view, the upper jaw is shaped like a right-angle triangle, the ventral margin being nearly straight and dorsal surface of the snout being gently sloped (Fig. 1). In dorsal and ventral views, the anterior snout (formed by the 
228 premaxillae) is shaped like a finely pointed triangle (Fig. 2); the posterior portion of the skull is

229 transversely expanded. Preserved bones of the skull roof (Figs 1-2, 5) include most of the

230 premaxillae, both maxillae, partial nasals, partial left lacrimal, partial prefrontals and

231 postfrontals, complete left and partial right jugals, nearly complete parietals, and partial

232 supratemporals. Some of these elements (e.g. portions of nasal and postfrontals) were too

233 fragmentary and/or poorly preserved to attach to the skull and are not part of the 3D model. The

234 left postorbital was originally present (Fig. 1A), but we were unable to locate the element. The

235 quadratojugals and squamosals are not preserved in BMT 1955.G35.1. The frontals are also

236 missing with the exception of a small fragment attached to the left nasal. Unless otherwise stated,

237 the morphology concurs with other specimens of the species (Lomax, Massare \& Mistry, 2017;

238 Lomax \& Massare, 2018).

Premaxilla. The premaxilla makes up two-thirds of the length of the cranium and most of the snout. The majority of both premaxillae are preserved, although portions of the posterior ends are missing including the margin of the external naris (Figs 1-2). The left premaxilla is more complete than the right element. In lateral view, the anterior premaxilla is dorsoventrally low but becomes progressively taller posteriorly. A longitudinal groove exposing a series of foramina (see below) along the lateral surface represents the fossa praemaxillaris (Figs 1B-C, 2). The right premaxilla preserves a long, tapering subnarial process that articulates with the maxilla and

247 extends to the middle of the maxilla (Figs 1B, 2A); the supranarial process is not preserved on 248 either side. Laterally, the contact between the premaxilla and maxilla is clear and consists of an 249 extensive scarf joint in which the ventral margin of the premaxilla laterally and dorsally overlaps 250 the anterior process of the maxilla (Figs 1-2). The contact between the premaxilla and maxilla on 
251 the palate is difficult to discern, although it appears that a maxillary shelf extends medially and

252 replaces the premaxillary shelf at the level of the $18^{\text {th }}$ preserved tooth on the right side. (The

253 teeth, were reset during conservation and their positions in the jaw are not original. However,

254 their reconstructed positions act as landmarks for our description.) Except at the anterior tip of

255 the snout, the premaxillae do not meet at the ventral midline.

256 In dorsal view, the premaxillae would have contacted each other at a butt joint for much

257 of their length, although they are largely separated due to deformation (Fig. 2E). Posteriorly, the

258 nasals inserted between the premaxillae. The dorsal margin of the left premaxilla laterally and

259 dorsally overlaps the nasal from approximately the level of the $13^{\text {th }}$ premaxillary tooth to its

260 broken posterior end. In dorsal view, a small, narrow portion of the anterior process of the nasal

261 is exposed; the rest is overlapped by the premaxilla.

262 Anteriorly, the premaxilla is a laterally bowed sheet of bone in transverse cross-section;

263 at the level of the seventh preserved tooth, it develops a medial shelf that roofs the alveolar

264 groove. From this point until its articulation with the maxilla, the premaxilla consists of a ventral

265 lamina that laterally overlaps the teeth, the medial shelf, and a dorsal lamina, which is deeply

266 grooved along its margin (as preserved on the right premaxilla), presumably to receive the nasal.

267 CT scans reveal that each premaxilla encloses a branching, longitudinal canal dorsal to the tooth

268 row (Fig. 2G-J). This canal extends from the posterior end of the premaxillary tooth row to the

269 third premaxillary tooth. Anteriorly, a series of short canals branch anterolaterally from the main

270 conduit and open onto the fossa praemaxillaris, either immediately above the alveolar margin or

271 on the dorsolateral aspect of the bone. The right premaxilla preserves five ventral and four dorsal

272 foramina; the left premaxilla preserves four ventral and one dorsal foramina. The posterior half

273 of each premaxilla contains two longer canals branching posteriorly from the main conduit, each 
274 of which opens onto posteriorly elongated grooves parallel to the alveolar margin of the

275 premaxilla. The left premaxilla preserves two additional longitudinal grooves on the posterior

276 half of its dorsolateral surface; however, these do not connect to the main canal within the

277 premaxilla. These vascular canals within the premaxilla (as well as those within the dentary, see

278 below) resemble canals in the facial bones of extant crocodilians and lepidosaurs, as well as

279 those reported in theropod dinosaurs (Dal Sasso et al., 2009), pliosaurs (Ketchum \& Benson,

280 2011; Foffa et al., 2014b), and plesiosaurs (Ketchum \& Smith, 2010) and something similar in

281 ichthyosaurs (Lomax \& Massare, 2015). In extant taxa, these canals carry neurovascular bundles

282 consisting of the maxillary artery and maxillary branch of the trigeminal nerve $\left(\mathrm{CN} \mathrm{V}_{2}\right)$ in the

283 upper jaw, and the inferior alveolar artery and mandibular branch of the trigeminal nerve $(\mathrm{CN}$

$284 \mathrm{~V}_{3}$ ) (Witmer, 1997). The complex web of ramifications reported in the upper jaw of pliosaurs

285 cannot be visualized in this specimen; this may be due to their absence, preservation or scan

286 resolution. Nonetheless, it is possible these canals were also associated with pressure or electro-

287 reception as seen in some extant taxa and as postulated for dinosaurs and pliosaurs (Foffa et al.

288 2014b).

289

290

Maxilla. Both maxillae are preserved, although the posterior portion of the left maxilla is missing

291

and both are damaged. In lateral view, the maxilla is a triangular bone with slender anterior and

292

posterior processes and is dorsoventrally tallest in its center (Figs 1-2). The anterior process is

293 longer and more delicate than the posterior process, which extends just under the orbit. Although

294 the external naris is not preserved, it is clear the maxilla extended well beyond the anterior end of

295 the external naris. 
297 section, the anterior maxilla has a ventral lamina that extends lateral to the tooth row, a ventrally

298 curving medial shelf (forming the dorsal and medial walls of the alveolar groove) and a short

299 dorsal lamina that contacts the medial surface of the premaxilla in a scarf joint. The dorsal

300 lamina of the maxilla, which underlaps the premaxilla, is exposed slightly anterior to the middle

301 of the left maxilla due to the damaged premaxilla. Posterior to the main body, the maxilla is

302 triangular in transverse section with a ridge on its dorsomedial surface that appears to articulate

303 with the short anterior process of the lacrimal, which is poorly preserved. An articulation surface 304 on the dorsolateral surface of the posterior process of the maxilla meets the jugal in a scarf joint, 305 separating the posterior process of the maxilla from the lacrimal.

307 Nasal. The anterolateral portion of the left nasal is preserved attached to the premaxilla (Figs 1-

308 2). It is best seen in ventral and posterior views, which reveals it is dorsoventrally thickened 309 medially but becomes dorsoventrally thin laterally. The bone is laterally bowed in transverse 310 section. The ventral margin of the nasal is laterally overlapped by the dorsal lamina of the

311 premaxilla; the morphology of the right premaxilla suggests this may have originally been a

312 tongue-and-groove contact. Near the posterior end of the element is a small fragment featuring a 313 grooved medial margin; it is unclear if this is a portion of the nasal or a fragment of the frontal.

314 CT scans reveal a few short canals penetrating the nasal from its lateral surface.

315 Other fragments of the nasal were found with the specimen but not mounted on the skull 316 due to their fragile nature. Although very fragmentary, much of the right nasal is preserved

317 although the posterior end is missing and it is impossible to determine the presence of an

318 internasal foramen. It is a long and delicate element that is wide posteriorly, and tapers to a point 
319 anteriorly (Fig. 5K-L). On the medial surface is a long groove that runs almost the entire length

320 of the nasal. The slightly flared lateral wing is damaged. Two foramina are present posteriorly,

321 positioned next to a portion of what may be the prefrontal.

322

323 Lacrimal. The left lacrimal is poorly preserved. It appears to be triradiate with a short, but

324 damaged anterior process and a longer posteroventral process. The dorsal process is tall and

325 formed the posterior margin of the external naris. It was clearly excluded from the orbital margin

326 by the anterior process of the prefrontal (Figs 1B, 2B,D). The lateral surface of the dorsal process

327 preserves external sculpting and several canals that penetrate the bone but cannot be traced. The

328 short, tapering anterior process fits onto a shelf on the dorsomedial aspect of the maxilla. The

329 posteroventral process, which is longer and mediolaterally wider than the anterior process, is

330 complete and contributes to the anteroventral margin of the orbit. It meets the dorsal margin of

331 the jugal in a curving contact. The lateral surface of the posteroventral process bears the remnant

332 of a ridge from its posterior tip to the base of the dorsal process.

334 Prefrontal. Only a small portion of the anterior process of the left prefrontal is present, although

335 original photographs of the mounted skull show that the element was once complete (Figs 1B,

336 2B). The anterior process of the prefrontal medially and dorsally laps the lacrimal along a broad

337 contact, where it is dorsoventrally tall and excludes the dorsal process of the lacrimal from the

338 orbital margin.

339

340

Postfrontal. The anterior portions of both postfrontals are preserved but were not added to the

341 mount. The right postfrontal is the more complete of the two elements (Fig. 5M). In dorsal view, 
342 the anterior end is mediolaterally broad and dorsoventrally thin. The postfrontal narrows

343 posteriorly, where it is damaged. The medial surface exhibits a prominent ridge.

345 Jugal. The jugal is a long, slender bone forming the ventral margin of the orbit; the left is better

346 preserved than the right (Figs 1-2). Anteriorly it is oval-shaped in transverse section and tapers to

347 a point, contacting the posteroventral margin of the lacrimal and dorsolateral aspect of the

348 posterior process of the maxilla as previously described. Although damaged and perhaps missing

349 a small portion, it is clear the anterior process extended to at least the level of the anterior margin

350 of the orbit. Posteriorly, the dorsal ramus of the jugal gently curves dorsally, expands

351 dorsoventrally and thins mediolaterally. Based on the original reconstruction (Fig. 1A), which

352 featured a complete jugal and postorbital, the jugal contributed to about half of the posterior 353 orbital margin.

Postorbital. An original photograph shows that the postorbital was complete, but we have been unable to locate the element (Fig. 1A). However, based on the photograph, it is clear that the postorbital is dorsoventrally short and anteroposteriorly wide, being almost rectangular in shape and making up half of the posterior orbital margin. The anterodorsal edge tapers to a narrow process.

Parietal. Both parietals are damaged and missing their anteroventral margins, the left element being better preserved (Figs 3, 5A-D). In dorsal view, the parietals are hour-glass shaped and meet medially, diverging slightly anteriorly. CT scans reveal the dorsomedial margin of the anterior parietal is strongly dorsoventrally expanded in transverse section, the elements 
365 contacting each other at a tall midline butt joint; the parietal thins ventrolaterally in transverse

366 section. The articulation of the parietals results in a well-defined sagittal crest (Fig. 5A, C); at its

367 mid-section, the parietal is L-shaped in transverse section with the horizontal leg forming the

368 roof of the braincase while the ventral leg forms the lateral wall of the braincase and medial wall

369 of the supratemporal fenestra. Lateral to the crest, the dorsal surface of the parietal is convex and

370 curves ventrally, widening posteriorly. Posteriorly, the crest decreases in height to form an

371 extensive shelf (parietal ridge) under which the supraoccipital articulates (Fig. 5A, C). Two

372 elongate depressions, one on the posterior aspect of each parietal, may represent attachment sites

373 for epaxial neck muscles (Fig. 5C).

In ventral view, the surface of the parietal is concave and bears impressions of structures that surrounded the brain (Fig. 5B, D). In the anterior region, impressions of the cerebral hemisphere and extra-encephalic depression are present (as in McGowan, 1973). McGowan

377 (1973, fig. 48) showed that the cerebral hemisphere was present in both the parietal and frontal in 378 a specimen of Ichthyosaurus. In BMT 1955.G35.1, there is no indication of the frontal at this 379 position, suggesting the cerebral hemispheres were likely limited to the parietal. The descending 380 parietal flange is present in both parietals, although the left is more complete (Fig. 5B, D). The anterior process is thick, short, and protrudes forwards, creating a ledge. Towards the center of the parietal is the large, ovoid impression of the optic lobe, the most prominent of the cerebral structures, situated posterior to the parietal flange (Fig. 5B). The epiterygoid process is not preserved. Posteriorly, the parietal flares laterally to form the paraoccipital process; in posterior view, this process is shaped like a bowtie and ventrally deflected. In ventral view, there may be an impression of the cerebellum, although this is difficult to confirm because this portion is damaged. 
389 Supratemporal. Portions of both supratemporals are preserved. The majority is exposed at the

390

391

392

393

394

395

396

397

398

399

400

401

402

403

404

405

406

407

408

409

410

posterior margin of the skull, attached to the parietal (Figs 3C, 5C). It is difficult to identify the parietal-supratemporal suture in the original specimen. In CT scans, the contact between the left parietal and supratemporal is visible as a very tight, sinuous butt joint; this contact cannot be discerned on the right and the two bones may have fused. In posterior view, the preserved supratemporal is large and triradiate; it is narrow medially and increases in width distolaterally, with a posteroventral process. In this view, it is roughened with numerous striae, probably for muscle attachment (Kirton, 1983) (Fig. 5C). There are also some foramina present, similar to those reported in this region of the supratemporal in ichthyosaurs such as the Cretaceous Leninia stellans (Fischer et al., 2014).

\section{Anatomical description of the palate}

The left pterygoid, including a fragment representing the quadrate wing, and quadrate are preserved (Fig. 3).

Pterygoid. The left pterygoid can be positively identified, although it is damaged. It is an anteroposteriorly elongate element with a robust and mediolaterally wide posterior end and narrow anterior end (palatal ramus) (Figs 3, 5E-F). The palatal ramus is dorsoventrally flattened and makes up over half the length of the pterygoid; it is narrowest at its mid-length and expands distally. Posteriorly, the pterygoid expands transversely and dorsoventrally to form the quadrate ramus; its dorsal surface rises in a ridge that would have been continuous with the quadrate wing (see below). Although damaged and incomplete, the overall morphology of this element, particularly how the shape changes from the posterior end to the narrow mid-shaft which then 
411 broadens anteriorly, is reminiscent to the pterygoid of Sveltonectes (Fischer et al., 2011, fig. 2G).

412 This differs from Ichthyosaurus, which has a very narrow shaft posteriorly (McGowan, 1973,

413 fig. 20), and from Platypterygius longmani Wade 1990 which has a mediolaterally wider shaft

414 (Kear, 2005, fig. 8C-E) and even from Ophthalmosaurus icenicus Seeley 1874, in which the

415 pterygoid has a distinctly different shape posteriorly (Moon \& Kirton, 2016, plate. 6, figs 1, 2).

416 In dorsal view, the posterior end has three wing-like projections. The medial projection,

417 which is damaged and was originally more extensive, is the largest and most robust, whereas the

418 lateral projection is slender and dorsoventrally flattened (Fig. 5E). The ventral surface is better

419 preserved, although the edge of the interpterygoid vacuity is damaged (Fig. 5F). Regardless, the

420 posterior end of the pterygoid is larger, wider, and narrows more gradually than that of

421 Ichthyosaurus (McGowan, 1973, fig. 20B). The dorsal (quadrate) wing of the posterior ramus of

422 the left pterygoid is almost certainly represented by a large but thin fragment of bone, the shape

423 of which was obscured by a large amount of wood and plaster in the original reconstruction but

424 is revealed in CT scans.

425

426 Quadrate. Only the left quadrate is preserved, which is a large and robust element (Figs 3, 5G-I).

427 In anterior and posterior views the quadrate is C-shaped, owing to strong curvature of the shaft

428 (Fig. 5G-H); it is more of an L-shape in Ichthyosaurus (McGowan, 1973, fig. 9). The articular

429 condyle is massive and greatly expanded mediolaterally, whereas the dorsal end is mediolaterally

430 thin. A well-defined ridge is present above the condyle and displays a long groove identified as

431 the quadratojugal facet. A groove is present on the ventral surface of the condyle, which divides

432 the jaw joint surface into two distinct faces as is common among ichthyosaurs. 
435 Preserved material includes the supraoccipital, left opisthotic, left stapes, and parabasisphenoid 436 (Fig. 3). The anterior portion of the parasphenoid as well as the basioccipital, prootics, and 437 exoccipitals are missing.

438 Supraoccipital. The median supraoccipital is triangular with its apex anterodorsally directed 439 (Fig. 6A-C). CT scans revealed that the right margin of the supraoccipital had been reconstructed 440 in plaster, obscuring the true shape of this element. In anterior and posterior views, the element is 441 convex and arch-like, and is wider than it is tall, which is similar in Ichthyosaurus (McGowan, 442 1973, fig. 4). Of particular note, in this view, the dorsal portion of the opening for the foramen 443 magnum is much more reduced than in either Platypterygius longmani (Kear, 2005, fig. 10D-E) 444 or Ophthalmosaurus icenicus (Moon \& Kirton, 2016, Plate 9, fig. 1-5). A median ridge is present on the posterior surface, which is sharpest anterodorsally and flattens as it approaches the 446 foramen magnum (Fig. 6B-C). This ridge would have contacted the parietal, as shown in the 3D 447 model (Fig. 3C, F) and separates two flat, posterolaterally-directed faces, each of which is 448 pierced by a canal that opens onto its internal surface (Fig. 3B, G). These openings probably 449 represent the foramen endolymphaticum (Andrews, 1910), which served for the passage of the endolymphatic ducts (McGowan, 1973; Maisch, 2002; Marek et al., 2015) or veins (Kirton, 1983; Moon \& Kirton, 2016). The complete left half preserves two articulation facets along its ventral lateral margin - a larger, posteroventrally-directed facet that is deep and triangularshaped (apex pointing forward) and a smaller, oval-shaped facet that is posterolaterally-directed. In dorsal view, there is a well-defined ridge that is separated by a long, trenchant groove 455 (Fig. 6B). For Ichthyosaurus, McGowan (1973, pg. 15) described the dorsal edge as having two 456 shallow grooves. The groove marks the boundary between the ossified and cartilaginous portions 
457 of the neurocranium (McGowan, 1973). In ventral view, the element is arched with a smooth

458 section for the roof of the foramen magnum (Fig. 6C). The exoccipital facet is roughly square.

459

460 Parabasisphenoid. The thin parasphenoid is broken with a small portion preserved fused to the

461 basisphenoid (Fig. 6D). The basisphenoid is complete and is a large, robust element both

462 mediolaterally wide and dorsoventrally tall (Fig. 6D-E). There are deep grooves between the

463 posterior corners of the bases of the basipterygoid processes and the main body for the palatal

464 ramus of the facial nerve (Kirton, 1983). In dorsal view, the midline of the anterior end is convex

465 and, along with the protruding anterior ends of the basipterygoid processes, gives the anterior

466 margin of the basisphenoid a 'three-pronged' appearance, resembling a specimen of

467 Ichthyosaurus referred to as the 'Evans Nodule' by McGowan (1973, plate 1a). The

468 basipterygoid processes are both complete, robust and oblong in ventral view (Fig. 6E). Their

469 surfaces appear slightly roughened, probably due to a cartilaginous covering for contact with the

470 pterygoid. The distal articular facet of the basipterygoid process is defined by a depression with a

471 rim. The anterior tip of the basipterygoid process is tapered, whereas the posterior margin is

472 thickened and rounded.

473 The anterodorsal aspect of the basisphenoid features a pair of robust protuberances

474 separated by a slight midline depression - the sella turcica - that housed the pituitary gland (Fig.

475 6D). Below this is the median opening for the carotid artery, which courses posteroventrally

476 through the bone and exits on its ventral surface as a rounded opening bounded proximally by an

477 arch-like ridge (Fig. 6D-E). Ventral to this opening and dorsal to the parasphenoid is a kidney-

478 shaped articulation facet, interpreted as the impressions of paired trabeculae (as in McGowan,

479 1973, fig. 1) (Fig. 6D). Immediately dorsal and posterior to the sella turcica, is a large, bulbous 
480 region that has the ossified dorsum sellae (dorsal crest). The posterior surface is a wide, rounded 481 rectangle, indented for reception of the basioccipital.

482

483 Opisthotic. Only the left opisthotic could be identified (Fig. 6F-G). It is a robust and stout 484 element that is roughly pentagonal in posterior view. Its ventrolateral margin is long and sharp.

485 Ventrally the opisthotic tapers to a point that bears a small facet, which articulates with the 486 stapes. The stapedial facet is large, but the lateral 'foot' (after Fischer et al., 2012) has minor 487 exposure. The ventromedial margin is concave and bears a long, low groove that marks the 488 basioccipital facet (Fig. 6G). The dorsolateral margin forms the prominent paroccipital process, the posterior surface of which bears a long, prominent ridge that ascends vertically from the ventral tip of the element, then turns medially. A deep groove, for either the glossopharyngeal or branch of the facial nerve (Kirton 1983; Marek et al., 2015), separates this ridge from a pronounced protuberance on the dorsal margin of the opisthotic. The dorsomedial margin is expanded into a rugose, subtriangular depression (apex pointing posterodorsally) surrounded by a raised lip and several small protuberances. Although poorly preserved, the membranous impressions of the posterior vertical semicircular canal, sacculus, the horizontal semicircular canal and possibly utriculus are represented by a somewhat 'V-shaped' impression, best observed in anteromedial aspect (Fig. 6F). The impression of the horizontal semicircular canal is damaged at the tip and the impression of the sacculus is wide and round. There are several grooves positioned adjacent to the impressions, which McGowan (1973, fig. 5) referred to as 500 grooves in the margin circumscribing the membranous impression. Computed tomography

501 reveals a great deal of trabecular bone within the opisthotic. 
503 Stapes. Both stapes are preserved, with the left being more complete. The stapes is

504 mediolaterally elongate with a bulbous occipital head and a tapered distal end (Fig. 6H). The

505 proximodorsal region of the medial head bears a groove that marks the course of the stapedial

506 artery. In anterior view, the medial head is laterally inclined and there is a shallow groove, which

507 is probably the opisthotic facet. The posterior surface of the stapes bears a series of oblique

508 ridges and grooves. This may have been an area for muscle attachment (McGowan, 1973, fig.

509 7a) (Fig. 6H). There are several small canals within the stapes; however, these are very difficult

510 to trace.

511

512 Anatomical description of the lower jaw

513 Nearly complete left and right dentaries are present, as are both incomplete splenials, the nearly

514 complete left surangular, and the complete left articular and angular (Fig. 4).

516 Dentary. The dentary makes up over three-quarters the length of the lower jaw. It is elongate,

517 tapering at its anterior and posterior ends (Figs 1, 4). The ventral margin is convex while the

518 dorsal margin is concave, and the entire element curves dorsally at its anterior end; the latter is

519 likely the result of taphonomic distortion. As with the upper jaw, the lower teeth have been reset

520 in a continuous groove, which we use as landmarks for our description. In transverse section, the

521 anterior dentary is roughly oval-shaped with a convex lateral surface; a medial shelf forms the

522 floor of the alveolar groove and a dorsal lamina laterally overlaps the dentary teeth. The medial

523 shelf is separated from a longitudinal ridge that parallels the ventral margin of the bone by a

524 shallow groove (lateral wall of the Meckelian canal); this ridge and groove dominate the internal

525 face of the anterior half of the dentary. At the level of the $15^{\text {th }}$ dentary tooth, the medial shelf 
526 disappears and the dentary becomes a laterally bowed sheet of bone with a thickened dorsal

527 margin in transverse section.

528 The anterior tip of the right dentary is damaged and, as a result, the dentaries do not

529 contact each other anteriorly to form the mandibular symphysis (Figs 1, 4). As preserved, the

530 dentary and splenial do not contact each other along their entire length but this is due to

531 distortion. The anterior tip of the angular is level with the $17^{\text {th }}$ preserved tooth on the right side;

532 the angular laterally overlaps the ventral margin of the dentary in a very tight scarf joint. In

533 contrast, the suture between the dentary and surangular, which reaches the level of the $22^{\text {nd }}$

534 preserved dentary tooth, is a loose, horizontal butt joint except at its posterior end where the

535 posterior tip of the dentary laterally overlaps the surangular.

536 As with the premaxilla, CT scans reveal that each dentary encloses an elongate,

537 branching canal ventral and lateral to the tooth row that extends from the anterior tip of the bone

538 to the $14^{\text {th }}$ (right) and $9^{\text {th }}$ (left) preserved dentary teeth, at which point the canal opens onto the

539 internal surface (Meckelian canal) of the lower jaw ventral to the medial shelf of the dentary

540 (Fig. 4C, G-J). Anteriorly, four small canals branch laterally from the main conduit and open

541 onto short, posteriorly elongated grooves on the lateral face of the dentary. A posterior (fifth)

542 canal opens into a very long groove ventral and parallel to the tooth row that extends over a

543 quarter the length of the dentary.

544

545 Splenial. The splenial is composed of a vertical sheet of bone that is medially concave, a slightly

546 thickened dorsal margin that is turned medially, and a thickened, laterally deflected ventral

547 margin. Thus, the element has a mild S-shape and is mediolaterally thin in transverse section

548 anteriorly, becoming more robust with increasingly pronounced curvature posteriorly. The 
549 splenial forms the medial wall and part of the floor of the Meckelian canal for the posterior half

550 of the lower jaw. Its contacts with other elements cannot be reliably interpreted as the bones

551 were not in articulation; however, from their preserved ventral margins, it appears the splenial

552 and angular met in a butt joint.

553

554 Angular. The angular extends over half the length of the lower jaw (Figs 1, 4B). The anterior half 555 of the angular is a long, straight rod while the posterior half is both dorsoventrally and

556 mediolaterally expanded, curving dorsally and medially towards the jaw joint. In transverse

557 section, the anterior half of the angular is diamond-shaped with a dorsomedial surface that

558 contacts the ventral margin of the dentary in a tight scarf joint and a dorsolateral surface that

559 meets the ventral margin of the surangular in a loose butt joint. The ventromedial surface of the 560 anterior angular bears a shallow, longitudinal groove bounded dorsally and ventrally by low

561 ridges that presumably articulated with the splenial. Posteriorly, the angular develops a robust

562 tab or lamina that extends from its dorsomedial surface and medially laps the surangular.

563 However, immediately ventral to the jaw joint, this lamina disappears and is replaced by taller,

564 mediolaterally thin dorsolateral lamina that extensively overlaps the lateral aspect of the

565 posterior surangular. Thus, the contact between the angular and surangular is morphologically

566 simple and loose anteriorly but tighter and more complex posteriorly. In lateral view, the anterior

567 end of the surangular is broken and it appears the angular extends further anteriorly than the

568 surangular (Fig. 4B). This is similar to specimen SOMAG 12, a referred specimen of

569 Protoichthyosaurus prostaxalis (Lomax, Massare \& Mistry, 2017).

570 
571 Surangular. The surangular is a long, curved element forming the lateral aspect of the posterior

572 third of the lower jaw (Figs 1, 4B). The anterior half of the surangular is poorly preserved as it is

573 mediolaterally thin and is loosely joined to the dentary (dorsally) and angular (ventrally) via

574 rounded butt joints. Posterior to the dentary, the dorsal margin of the surangular thickens

575 dramatically to form the peaked coronoid process. A longitudinal lateral ridge, dorsally bounding

576 the fossa surangularis, continues to the end of the surangular and separates the thickened dorsal

577 margin from the thinner ventral lamina that articulates with the angular. The element expands

578 dorsally and medially at its rounded posterior end to laterally cup the articular.

579 In medial view, the posterior surangular bears a ridge parallel to its ventral margin that

580 articulates with the angular and forms the floor of the adductor fossa. There is another, more

581 robust ridge on the medial surface originating at the coronoid process and widening posteriorly

582 to contact the anterior surface of the articular. The medial face of the surangular between the two

583 ridges is concave and forms the Meckelian groove and lateral wall of the adductor fossa. There is

584 a large foramen clearly visible on the medial aspect ventral to the coronoid process; this foramen

585 passes laterally through the surangular and exits ventral to the ridge on the lateral surface (Fig.

$5864 \mathrm{D}, \mathrm{K})$.

587

588 Articular. The preserved left articular has a triangular profile in dorsal and ventral views, with 589 the apex posteriorly and medially directed, and a subcircular profile in medial and lateral views.

590 The posterior margin is sharp while the anterior aspect is flat and broad where it contacts the

591 quadrate to form the jaw joint. The medial aspect of the bone is smooth while the lateral aspect is

592 pitted and porous. CT scans reveal several small, short canals that penetrate into the bone from

593 its lateral surface. 
595 Hyoid. Both hyoids are preserved and are large and complete, although some damage is

596 apparent. The hyoid is a curved, rod-like bone (Fig. 5J). In dorsal view, the element is slightly

597 bowed posterolaterally and the center of the element is slightly mediolaterally narrower than

598 either end. The anterior end is slightly flattened, rounded and pitted for reception of cartilage. In

599 anterior view, the probable left hyoid is oval-shaped, with a defined rim.

600

601

Dentition. The teeth were implanted in an aulacodont fashion in continuous alveolar grooves as

602 is typical in euichthyosaurs. As previously mentioned, the teeth were not preserved in situ and

603 were added to the grooves during reconstruction of the skull both in 1955 and in 2015; thus, they

604 are not in their original positions. Furthermore, the dental groove is too poorly preserved to

605 determine the exact number of teeth that would have originally been present. There are

606 additional fragmentary and complete teeth associated with the specimen.

607 The teeth are lingually curved, large cones with short, robust crowns with fine striations

608 and smooth apices (Figs 1B-C, 5N). In complete teeth, the crown is much narrower than the root.

609 The roots are large with prominent longitudinal grooves that extend to the base of the crown and

610 continue as longitudinal striations on the crown (Fig. 5N). This morphology is found in all

611 specimens of Protoichthyosaurus that have well-preserved teeth (Lomax, Massare \& Mistry,

612 2017; Lomax \& Massare, 2018). Tooth morphology for each tooth is similar, with crowns

613 ranging from $0.87 \mathrm{~cm}$ to $1.75 \mathrm{~cm}$ in height. As no teeth were preserved in situ, it is impossible to

614 differentiate between the premaxillary, maxillary and dentary teeth. A resorption pit is present on

615 the lingual surface in many teeth (e.g. Fig. 5N). CT scans reveal hollow pulp cavities within the

616 teeth that open at the tooth bases and extend nearly the entire height of the tooth. 
618 Anatomy of the postcranial skeleton.

619 Portions of the vertebral column, ribs, gastralia, forefin, pectoral girdle, pelvic girdle and the

620 hindfin are preserved (Fig. 7). The forefin and hindfin phalangeal elements are entirely free of

621 matrix and are not in their original context, so it is impossible to say whether elements are from

622 the left or right fin.

623

624 Axial skeleton. A total of 37 vertebral centra are present, all of which are disarticulated. Most are 625 poorly preserved but their positions in the column can be identified from their morphology. One 626 centrum is unusual in possessing the following features: triangular in anterior and posterior

627 views; being marginally anteroposteriorly longer than the preserved cervicals; diapophyses and 628 parapopthyses being high and positioned at the anterior end of the centrum in lateral view; two 629 separate semi-circular facets for articulation with intercentra in ventral view (Fig. 7A-B). This 630 morphology is indicative of an atlas-axis complex, but the centrum displays no fusion. This is 631 unusual given that, with the possible exception of immature individuals and some early Triassic 632 taxa, the atlas-axis is always fused in ichthyosaurs (McGowan \& Motani, 2003; VanBuren \& 633 Evans, 2017). The presence of two facets on the ventral surface might suggest that this element is 634 the atlas, with the diagonally-oriented anterior facet being for the atlantal intercentrum and the 635 posterior facet for the axial intercentrum (Fig. 7B). Alternatively, and more likely, this is the 636 axis, with the anterior facet being for the axial intercentrum and the posterior facet being for the 637 intercentrum of the third cervical vertebra (McGowan \& Motani, 2003, fig. 5C). Interestingly, 638 the anterior surface of the axis centrum is not well-defined, nor smooth and lacks the convexity 639 typical of ichthyosaur centra (Fig. 7A). This might be pathological or it could be the surface that 
640 was fused with the atlas vertebra that is not usually preserved (or exposed). A second centrum

641 features similar morphology but is slightly anteroposteriorly shorter and has only one small,

642 anterior facet on the ventral surface, which articulates with the aforementioned vertebra. It is

643 likely that this is the centrum of the third cervical vertebra. The remaining vertebral centra

644 include 19 dorsals, including elements from the anterior, middle and posterior portions of the

645 series as identified by their shape and position of the diapophyses and parapopthyses, and 16

646 caudal vertebra, again including elements from the anterior, middle and posterior portions of the

647 series as identified by their shape and the presence of a single rib facet.

648 One isolated and damaged neural spine, which is mediolaterally thin at its distal end, is

649 preserved.

650 Numerous incomplete ribs and rib fragments are preserved. The cross-sectional geometry

651 of the ribs varies, with some being rounded whereas others have a dumbbell-shaped cross

652 section. A possible gastralia fragment is present, which is roughened at its anterior end where it

653 presumably met its counterpart at the midline.

654

655 Pectoral girdle. The left coracoid is practically complete (Fig. 7C). It is a robust element that is

656 slightly anteroposteriorly longer than mediolaterally wide (Table 1). It has prominent and well-

657 developed anterior and posterior notches. The anterior notch is wider than the posterior notch,

658 resulting in the posterior end of the coracoid being mediolaterally wider than the anterior end. A

659 prominent rim outlines the glenoid and scapular facets, the former being noticeably longer than

660 the latter. In medial view, the intercoracoid facet is dorsoventrally thickened and bulbous at the

661 anterior end but narrows posteriorly. 

anterodorsal end is marked by a right angle, which extends to the ventral edge. This proximal end is twice as tall dorsoventrally as the mid shaft and is widely flared but without a prominent 665 acromion process.

667 Forefin. As mentioned previously, none of the phalangeal elements were found in articulation. It 668 is impossible to determine whether the elements are from the left or right fin or determine the 669 morphology of the forefin in this specimen. The radius and ulna are missing and the preserved 670 elements are polygonal. Of note, the forefin was reconstructed for display in 1955 and 2015 with 671 the morphology typical of Ichthyosaurus (Motani, 1999). This was prior to the resurrection of 672 Protoichthyosaurus (Lomax, Massare \& Mistry, 2017).

674 proximally without a prominent constriction in the mid shaft (Fig. 7E-F). It is the largest 675 humerus of Protoichthyosaurus described thus far (Table 1). The proximal end is large, bulky 676 and the surface is rugose and roughened. In ventral view, the deltopectoral crest is offset 677 anteriorly and is large but does not extend far down the shaft. The base of the anterior end is 678 slightly flared due to the presence of an anterior facet. The dorsal process is broken but appeared 679 centrally located. There are several possible predation marks preserved on the ventral surface of 680 the humerus (Fig. 7F). The facets for the radius and ulna are also damaged.

Pelvic girdle. A single ilium is well-preserved (Fig. 7G). It is a relatively thick and elongate element that is J-shaped in lateral and medial views, resembling the ilium of Ichthyosaurus 684 somersetensis in being more oblong than rib-like (Lomax \& Massare, 2017). The presumed 
685 posterior end is slightly bulbous, relative to the shaft, somewhat similar to the ilium of

686 Protoichthyosaurus applebyi (Lomax, Massare \& Mistry, 2017, UNM.G.2017.1). The presumed

687 anterior end is highly rugose. A possible ischium might also be preserved, but it is heavily

688 damaged.

689

690 Hindfin. Like the forefin, some phalanges of the hindfin are preserved, which are largely

691 polygonal, but none were found in articulation and all have lost their original context.

692 Regardless, the single, incomplete femur provides information (Fig. 7H-I). As the proximal end 693 is poorly preserved, it is difficult to identify the element as being from the left or right, but it is

694 most likely a right femur, based on the following comments. It has a very slender shaft, narrow 695 proximal end, and a flared distal end. Both the dorsal and ventral processes are damaged and 696 worn, but the supposed dorsal process seems to be a prominent, narrow ridge and the supposed 697 ventral process is large. There is a slight flare at the anterior end, but the posterior end is only 698 slightly expanded, and is almost a right angle. The tibial facet is larger than the fibular facet.

699

700

Historically modelled regions of the skull of BMT 1955.G35.1

701 CT-scanning the skull of BMT 1955.G35.1 aided substantially in our anatomical description.

702 Additionally, modelled areas of the skull can be clearly differentiated from fossil bone in scans

703 by the differing densities of these materials (Fig. 8). Fossil bone is the densest material

704 (appearing as bright areas within CT scans) followed by regions of the braincase that were 3D

705 printed in gypsum (see Material and Methods). Areas of the skull modelled during its initial

706 reassembly post-May 1955 are the least dense, as they are either composed of wood or a

707 traditional mix of alvar, jute and kaolin (known as AJK dough). Some modelled areas - such as 
708 the posterior third of the right lower jaw, central portion of the right jugal, and "symphysis"

709 between left and right dentaries - are immediately apparent. Other areas, including the right

710 lacrimal and prefrontal, and various patches in the lower jaws, are less obvious. The skillfully

711 modelled right margin of the supraoccipital is only evident in CT scans, as are portions of the

712 braincase that were 3D printed and added to the newly reassembled skull. Thus, our work

713 demonstrates the utility of applying CT scanning to older, potentially modified museum

714 specimens to better understand both anatomy and specimen history.

715

716

$3 D$ digital reconstruction of the skull of BMT 1955.G35.1

717 Limits to the data set used in the 3D digital reconstruction of the skull must be noted. Numerous

718 bones are absent, fragmentary or were too delicate to scan, and some aspects of the 3D

719 reconstruction are uncertain. For example, the width of the reconstructed skull is constrained by

720 the articulation of the premaxillae (anteriorly) and contacts between the basisphenoid, pterygoids

721 and quadrate (posteriorly). Bones of the skull roof and palate that determine width in the middle

722 part of the skull are missing. Furthermore, the placement of the preserved bones of the posterior

723 skull roof is an estimate based on 1) the predicted height of the missing exoccipitals relative to

724 other braincase elements, and 2) the assumption of a smooth slope between the nasals and

725 parietals, as observed in other large ichthyosaurs, including examples of the genus

726 Protoichthyosaurus (Lomax, Massare \& Mistry, 2017; Lomax \& Massare, 2018). We did not

727 attempt to retrodeform elements that experienced plastic deformation, specifically the lower

728 jaws. The exaggerated dorsal and lateral curvature of these elements prevents complete closure

729 of the upper and lower jaws in our model. Similarly, the premaxilla and nasals could not be

730 completely re-articulated due to their deformed nature. Thus, this $3 \mathrm{D}$ digital reconstruction is our 
731 current best hypothesis of the original skull shape of BMT 1955.G35.1 based on preservation and

732 personal interpretation. With these limitations in mind, the digital reconstruction nonetheless

733 yields useful new information on overall skull shape in this taxon (Fig. 9; Appendix S3). This

734 skull shape is typical of Protoichthyosaurus prostaxalis in lateral view (Fig. 9A), in having a low

735 skull that is slightly inclined from the nasals to the posterior end of the skull and in possessing a

736 relatively long and slender rostrum especially when compared with Lomax et al., (2017, figs. 2C,

737 4A-B) and Lomax and Massare (2018, figs. 2-3).

738 Due to the limitations of the fragile nature of the specimen some of the bones could not

739 be articulated in life position in the physical model and there are differences between the digital

740 and physical (Figs. 1, 2; Appendix S1) models. Of note, the rear of the skull is mediolaterally

741 wider and dorsoventrally shorter in the digital reconstruction than in the physical model. This is

742 due to placement of the basisphenoid dorsal and anterior to its true articulation with the

743 pterygoids in the physical model, as well as midline contact between the pterygoids; the

744 pterygoids are separated by the basisphenoid in ichthyosaurs (McGowan, 1973, Kirton, 1983;

745 Kear, 2005). The stapes is dorsally displaced in the physical reassembly; in other ichthyosaurs,

746 the stapes contacts the quadrate dorsal to its expanded base (Andrews, 1910; Kirton, 1983;

747 McGowan \& Motani, 2003). Lastly, the jugal extends posterior to the quadrate in the physical

748 model, leaving no space for the posterior facial bones and resulting in the upper jaw being

749 anteroposteriorly shorter than the lower jaw. Shifting premaxilla and contacting bones so that the

750 anterior tips of the premaxillae and dentaries are level results in a gap between the jugal and

751 quadrate large enough to accommodate the missing postorbital and quadratojugal. These

752 differences highlight another advantage of applying 3D imaging and visualization methods to

753 large specimens. Large fossil bones are fragile and heavy, and there are practical limitations to 
754 how they can be physically manipulated and mounted when reassembling a skull or skeleton;

755 digital manipulation of fossil bones reduces risk to the specimen and errors can be easily

756 corrected.

757

758 Discussion

759

760

761

762

763

764

765

766

767

768

769

770

771

772

773

774

775

776

BMT 1955.G35.1 has never formally been described. The original museum record shows that it was initially identified as Ichthyosaurus communis, a species to which many ichthyosaur specimens were historically referred as it is among the most common ichthyosaurs in the UK (but see Massare \& Lomax, 2017). In notes held at the Warwickshire Geological Records Service (pers. comm. J. Radley, 2015), a report by Dr Brian Seddon, stated: "It is believed that this animal is a new species lying somewhere between communis [I. communis] and breviceps $[I$. breviceps]". A 1957 letter from Seddon states that it was ichthyosaur expert Robert Appleby who expressed the opinion that the specimen possibly represented a new species and requested photos be taken. More recently, Larkin et al. (2016) tentatively identified the specimen as Ichthyosaurus, based on available information at the time. Since then, a revised diagnosis of Ichthyosaurus has been published (Massare \& Lomax, 2017), along with a redescription of Protoichthyosaurus (Lomax, Massare \& Mistry, 2017), a genus first described by Appleby (1979), which was later synonymized with Ichthyosaurus (Maisch \& Hungerbühler, 1997). Lomax et al. (2017) provided an emended diagnosis of Protoichthyosaurus, which included several autapomorphies of the forefin. Lomax and Massare (2018) provided additional information on the genus and species, including a revised diagnosis, and showed that the genus can also be distinguished from Ichthyosaurus by a combination of skull characters. They further noted that characters used to distinguish individual species of Protoichthyosaurus from 
777 individual species of Ichthyosaurus are more easily evaluated. The forefin of BMT 1955.G35.1

778 is entirely reconstructed and we have been unable to locate photographs or illustrations of how

779 the freshly excavated forefin appeared. Thus, the forefin cannot be used to identify the specimen.

780 BMT 1955.G35.1 does possess features shared by both Ichthyosaurus and

781 Protoichthyosaurus, including: a coracoid with both prominent anterior and posterior notches;

782 scapula with a narrow shaft that is expanded at the anterior end, but without a prominent

783 acromion process; a humerus with nearly equal width distally and proximally, with only a slight

784 constriction in the shaft; and femur longer than wide, with distal end wider than proximal end.

785 BMT 1955.G35.1 can, however, be assigned to Protoichthyosaurus on the basis of several

786 characters. Some of these characters are also found in some species of Ichthyosaurus but not in

787 the same combination (Lomax \& Massare, 2018). They include: the prefrontal anterior process

788 separates the lacrimal dorsal process from the orbit margin; strongly asymmetric maxilla with

789 long, slender anterior process; teeth that have large roots with deep, prominent grooves that

790 extend to the base of the crown and are continuous with the ornamentation of the crown itself;

791 and a long, slender rostrum. In addition, the slightly diverging anterior end of the parietals in

792 BMT 1955.G35.1, which leaves an opening at the anterior end, is indicative of the posterior

793 opening for the pineal foramen between the parietals and frontals. Because the frontals are not

794 preserved, it is not possible to confirm if this is correct, but it seems plausible as this is the

795 position of the pineal in Protoichthyosaurus (Lomax \& Massare, 2018). In Ichthyosaurus the

796 pineal is between the frontals and parietals (Massare \& Lomax, 2017).

797

Protoichthyosaurus prostaxalis and P. applebyi differ in skull and humeral morphologies

798 (Lomax, Massare \& Mistry, 2017). A third questionable species, P. fortimanus, known only from

799 an isolated forefin missing the humerus, displays only characters of the genus (see discussion in 
800 Lomax \& Massare, 2018). The left humerus of BMT 1955.G35.1 is damaged on its dorsal

801 surface. This restricts its usefulness in identification because the two species can be

802 differentiated by the dorsal process, which is missing in this specimen. The humerus of BMT

803 1955.G35.1 is robust, more similar to $P$. prostaxalis than $P$. applebyi, but this may be due to the

804 large size of BMT 1955.G35.1 (see Lomax, Massare \& Mistry, 2017, fig. 5). However,

805 considering the size, Lomax and Massare (2018) recently described the second known specimen

806 of P. applebyi, an isolated skull (NHMUK R1164), which is comparable in size with some

807 smaller specimens of $P$. prostaxalis. They identified NHMUK R1164 as probably an adult and

808 showed that the differences among the two species are not ontogenetic. BMT 1955.G35.1 is

809 more than twice the size of NHMUK R1164 and is probably an adult $P$. prostaxalis.

810 Unfortunately, BMT 1955.G35.1 is missing some features of the skull that distinguish the two

811 species. However, the maxilla of BMT 1955.G35.1 is large, triangular, dorsoventrally high, and

812 possesses a long and narrow anterior process that is longer than the posterior process. In $P$.

813 applebyi, the maxilla is dorsoventrally low. Furthermore, although the jugal is incomplete and

814 the postorbital is missing, they were complete and part of the original mount (Fig. 1A). The

815 morphology of the postorbital, although based on the interpretation of a photograph, in being

816 dorsoventrally short but anteroposteriorly wide almost rectangular, and making up half of the

817 posterior orbit margin are characters found in P. prostaxalis (Lomax, Massare \& Mistry, 2017;

818 Lomax \& Massare, 2018). In P. applebyi, the postorbital is dorsoventrally long, anteroposteriorly

819 narrow, and makes up much more than half of the orbit posterior margin (Lomax \& Massare,

820 2018). Consequently, even accounting for a misinterpretation of the postorbital morphology, its

821 shape does not match what is found in P. applebyi. Thus, based on the morphology and extent of

822 the maxilla and postorbital, we assign the studied specimen to $P$. prostaxalis. The difference in 
823 size between the studied specimen and the presumed adult specimen of $P$. applebyi (NHMUK

$824 \mathrm{R} 1164)$ is another indicator that the studied specimen belongs to P. prostaxalis.

It should also be noted that the maxilla of BMT 1955.G35.1, although dorsoventrally

826 high, does not appear as tall as in some specimens of $P$. prostaxalis (e.g. BRLSI 3555, BU

827 5323), but this is due to damage to the dorsal lamina of the maxilla on both sides. It may also

828 appear shorter due to the length of the studied skull, which is almost twice that of the largest

829 reported specimen of $P$. prostaxalis (Lomax, Massare \& Mistry, 2017; Lomax \& Massare, 2018),

830 with an estimated total skull length of at least $80 \mathrm{~cm}$ and estimated mandible length of $87 \mathrm{~cm}$.

831 This is also much larger than the sister taxon Ichthyosaurus, with maximum skull and mandible

832 lengths of $57.5 \mathrm{~cm}$ and $67 \mathrm{~cm}$ respectively (Lomax \& Sachs, 2017). Considering that the skull

833 length is approximately $20-25 \%$ of the total body length, based on a paratype specimen of $P$.

834 prostaxalis (BRLSI M3555), we estimate BMT 1955.G35.1 would have been between 3.2 and 4

$835 \mathrm{~m}$ in length. This is the largest example of the genus known, the previous total length estimate

836 being $2.5 \mathrm{~m}$ (Lomax, Massare \& Mistry, 2017). The largest unequivocal example of

837 Ichthyosaurus has a maximum total body length estimate of $3.3 \mathrm{~m}$ (Lomax \& Sachs, 2017), thus

838 the maximum length estimate of the specimen described herein is also larger than all known

839 examples of Ichthyosaurus.

840

\section{Conclusions}

842 In this study, we describe a large, partial ichthyosaur skeleton from the Early Jurassic of

843 Warwickshire, England. In addition to examining the specimen, we carried out CT scanning of

844 individual skull bones as well as the entire, reassembled skull, one of the first times the skull of a

845 large marine reptile has been successfully CT-scanned, visualized and reconstructed in 3D (see 
846 McGowan, 1989; Foffa et al., 2014a). CT scanning contributed greatly to our anatomical

847 description by revealing features not visible on original fossil material such as: branching,

848 longitudinal vascular canals within the premaxilla and dentary; short canals penetrating the nasal,

849 lacrimal, stapes, and articular; trabecular bone within the opisthotic; canals in the basisphenoid

850 and supraoccipital; the presence of the quadrate process of the pterygoid; and the sutural

851 morphology. We also demonstrate the utility of applying medical imaging techniques to historic

852 specimens to differentiate between original fossil material and reconstructed regions, as well as

853 the advantage of using digital visualization to accurately reconstruct large fossil specimens in

$8543 \mathrm{D}$.

The detailed description of the three-dimensional skull and braincase presented herein

856 also provides information that can be used in phylogenetic studies. Although incomplete, the

857 skull and braincase preserve various elements that have not previously been reported or

858 described in any specimen of Protoichthyosaurus and therefore it provides more information

859 about this taxon so that its phylogenetic position can be explored in more detail. Furthermore,

860 our study has found additional characters that may lend further support for the distinction of

861 Protoichthyosaurus from its sister taxon Ichthyosaurus, such as the morphology of the pterygoid

862 and anteroventral surface of the parietal, which differ from that described for Ichthyosaurus

863 (McGowan, 1973). However, considering that only a couple of specimens preserve these

864 elements, it is possible that the differences may be the result of individual variation; more three-

865 dimensional specimens of both taxa are needed to test and clarify these findings.

866 Based on a unique combination of characters, we identify the specimen as

867 Protoichthyosaurus prostaxalis. With a skull nearly twice as long as any previously described

868 specimen of $P$. prostaxalis, this specimen greatly increases the known size range of this genus. 
869 Compared with known, contemporaneous Sinemurian ichthyosaurs, the estimated size suggests it 870 was larger than all species of Ichthyosaurus (Lomax \& Sachs, 2017), and comparable with the

871 largest known specimens of Leptonectes tenuirostris (McGowan, 1996a), but smaller than

872 Leptonectes solei (McGowan, 1993), Excalibosaurus costini (McGowan, 2003) and

873 Temnodontosaurus platyodon (McGowan, 1996b). Thus, our study also provides new

874 information on ichthyosaur diversity and potential ecology in the Early Jurassic of the UK.

\section{Acknowledgements}

877 Firstly, we would like to thank Luanne Meehitiya (formerly of TSM) who first discussed BMT 878 1955.G35.1 with NRL and DRL, and provided access to study the specimen. We would like to 879 express our thanks to each of the funders, which led to the scientific study and description of the 880 specimen. Thanks to Marta Fernández, Benjamin Moon and Alfio Chiarenza for their thorough and constructive reviews of this manuscript, which were greatly appreciated. We also thank

882 Lukas Large (TSM) for assistance and the Birmingham Museums Trust for the photos 883 reproduced in Figure 1B and 1C. Judy Massare and Valentin Fischer are acknowledged for 884 helpful comments on the morphology of the skull. Jon Radley provided information on the 885 geology of the site and records relating to the excavation. David Ward identified the shark tooth and provided stratigraphic information about the species. Michael Howarth identified the

887 ammonite associated with the postcranial skeleton and the ammonites recently collected by NRL

888 from the original site. The current landowner R. E Morley and the tenant farmer Robert Heath 889 gave permission for large holes to be dug at the site and Malcolm Bryan and Sally Bryan (son 890 and wife of the original finder of the specimen, Michael Bryan) and Clive Jeffries assisted with 891 the fieldwork. Robert Asher and Colin Shaw (University of Cambridge) provided access to 
892 microCT-scanning facilities; Renate Weller (Royal Veterinary College) carried out CT-scanning 893 of the full skull. Technical support for Avizo was provided by Alejandra Sánchez-Eróstegui and 894 Jean Luc-Garnier (Thermo Fisher Scientific). Steven Dey (ThinkSee3D) mirrored microCT data 895 and 3D printed the missing bones on the right side of the skull.

896

897 Data and Materials

898 Original CT data of the full skull is available at MorphoSource, here:

899 https://www.morphosource.org/Detail/MediaDetail/Show/media_id/29156. Raw microCT data 900 of individual braincase elements is not available as these data were lost; however, STLs and 3D 901 PDFs of these elements are available (see here:

902 https://www.morphosource.org/Detail/MediaDetail/Show/media_id/33743) and all elements that 903 were individually scanned were also scanned with the full skull.

904

905 Supporting information

906 Additional Supporting Information can be found in the online version of this article:

907 Appendix S1. 3D PDF of segmented CT scans of the reassembled skull of Protoichthyosaurus 908 prostaxalis (BMT 1955.G35.1). Download the PDF file and click once on the skull to activate.

909 Left-click to rotate the model; right-click to zoom in or out; and hold both buttons to pan. Check 910 or uncheck boxes in the model tree in the upper left corner of the viewer to display or hide 911 individual parts.

912 Appendix S2. Transformation matrices for the 3D digital reconstruction of Protoichthyosaurus 913 prostaxalis (BMT 1955.G35.1) from original CT data. 
914 Appendix S3. 3D PDF of the reconstructed skull of Protoichthyosaurus prostaxalis (BMT 915 1955.G35.1).

916

\section{References}

918 Andrew, CW. 1910. A descriptive catalogue of the marine reptiles of the Oxford Clay. Part I.

919 British Museum (Natural History), London, 205 pp.

920 Appleby RM. 1979. The affinities of Liassic and later ichthyosaurs. Palaeontology 22:921-946.

921 Benton MJ, Spencer PS. 1995. Fossil Reptiles of Great Britain. Chapman and Hall, London, 386

$922 \mathrm{pp}$.

923 Benton MJ, Taylor MA. 1984. Marine reptiles from the Upper Lias (Lower Toarcian, Lower

924 Jurassic) of the Yorkshire coast. Proceedings of the Yorkshire Geological Society 44:399-429.

925 Bonaparte CL. 1841. A new systematic arrangement of vertebrated animals. Transactions of the

926 Linnean Society of London 18:247-304.

927 Button D, Barrett P, Rayfield E. 2016. Comparative cranial myology and biomechanics of

928 Plateosaurus and Camarasaurus and evolution of the sauropod feeding apparatus.

929 Palaeontology 59:887-913.

930 Cox P, Rinderknecht A, Blanco R. 2015. Predicting bite force and cranial biomechanics in the

931 largest fossil rodent using finite element analysis. Journal of Anatomy 226:215-223.

932 Dal Sasso C, Maganuco S, Cioffi A. 2009. A neurovascular cavity within the snout of the 933 predatory dinosaur Spinosaurus. First International Congress on North African Vertebrate

934 Palaeontology, 22-23.

935 d’Orbigny A. 1842-1851. Paléontologie française. Terrains jurassiques. Tome I. Cephalopodes. 936 Masson, Paris, $642 \mathrm{pp}$. 
937 De Blainville HD. 1835. Description de quelques espèces de reptile de la Californie, précédée de

938 l'analyse d'un système general d'Erpétologie et d'Amphibiologie. Nouvelles

939 Annales du Muséum d'Histoire Naturelle 4:233-295.

940 Delair JB. 1969. A history of the early discoveries of Liassic ichthyosaurs in Dorset and

941 Somerset (1779-1835). Proceedings of the Dorset Natural History and Archaeological Society

942 90:1-9.

943 Edmonds EA, Poole EG, Wilson V. 1965. Geology of the country around Banbury and Edge

944 Hill: (explanation sheet 201, new series). HMSO.

945 Fernández M, Carabajal A, Gasparini Z, Diaz G. 2011. A metriorhynchid crocodyliform

946 braincase from northern Chile. Journal of Vertebrate Paleontology 31:369-377.

947 Fischer V, Masure E, Arkhangelsky MS, Godefroit P. 2011. A New Barremian (Early

948 Cretaceous) ichthyosaur from western Russia. Journal of Vertebrate Paleontology 31:1010-

$949 \quad 1025$.

950 Fischer V, Maisch MW, Naish D, Kosma R, Liston J. 2012. New ophthalmosaurid ichthyosaurs

951 from the European Lower Cretaceous demonstrate extensive ichthyosaur survival across the

952 Jurassic-Cretaceous boundary. PLoS ONE 7:e29234.

953 Fischer V, Arkhangelsky MS, Uspensky GN, Stenshin IM. 2014. A new Lower Cretaceous

954 ichthyosaur from Russia reveals skull shape conservatism within Ophthalmosaurinae. Geological

955 Magazine 151:60-70.

956 Fischer V, Bardet N, Benson BJ, Arkhangelsky MS, Friedman M. 2016. Extinction of fish-

957 shaped marine reptiles associated with reduced evolutionary rates and global environmental

958 volatility. Nature Communications 7: 10825. 
959 Foffa D, Cuff A, Sassoon J, Rayfield E, Mavrogordato M, Benton M. 2014a. Functional anatomy

960 and feeding biomechanics of a giant Upper Jurassic pliosaur (Reptilia: Sauropterygia) from

961 Weymouth Bay, Dorset, UK. Journal of Anatomy 225:209-219.

962 Foffa D, Sassoon J, Cuff A, Mavrogordata M, Benton M. 2014b. Complex rostral neurovascular

963 system in a giant pliosaur. Naturwissenschaften 101:453-456.

964 Herrera Y, Fernández M, Gaspirini Z. 2013. The snout of Cricosaurus araucanensis: a case

965 study in novel anatomy of the nasal region of metriorhynchids. Lethaia 46:331-340.

966 Jasinoski S, Rayfield E, Chinsamy A. 2009. Comparative feeding biomechanics of Lystrosaurus

967 and the generalized dicynodont Oudenodon. Anatomical Record 292:862-874.

968 Kear B. 2005. Cranial morphology of Platypterygius longmani Wade, 1990 (Reptilia:

969 Ichthyosauria) from the Lower Cretaceous of Australia. Zoological Journal of the Linnean

970 Society 145:583-622.

971 Ketchum HF, Smith AS. 2010. The anatomy and taxonomy of Macroplata tenuiceps

972 (SAuropterygia, Plesiosauria) from the Hettangian (Lower Jurassic) of Warwickshire, United

973 Kingdom. Journal of Vertebrate Paleontology 30:1066-1081.

974 Ketchum HF, Benson RBJ. 2011. The cranial anatomy and taxonomy of Peloneustes philarchus

975 (Sauropterygia, Pliosauridae) from the Peterborough Member (Callovian, Middle Jurassic) of the

976 United Kingdom. Palaeontology 54:639-665.

977 Kirton AM. 1983. A review of British Upper Jurassic ichthyosaurs. Unpublished PhD thesis,

978 University of Newcastle upon-Tyne, $239 \mathrm{pp}$.

979 Larkin NR, Lomax DR, Meehitiya L, Dey S. 2016. The discovery in a museum collection of the

980 largest known skeleton of Ichthyosaurus in the world and its re-display, including 3D-printing 
981 missing bones. The Annual Symposium of Vertebrate Palaeontology and Comparative Anatomy.

982 Vol 64, p. 12.

983 Larkin NR, O’Connor S, Parsons D. 2010. The virtual and physical preparation of the Collard 984 plesiosaur from Bridgwater Bay, Somerset, UK. The Geological Curator 9:107-116.

985 Lautenschlager S. 2016. Reconstructing the past: methods and techniques for the digital 986 restoration of fossils. Royal Society Open Science 3:doi: 10.1098/rsos.160342.

987 Lautenschlager S, Witmer L, Aaltangerel P, Zanno L, Rayfield E. 2014. Cranial anatomy of 988 Erlikosaurus andrewsi (Dinosauria, Therizinosauria): new insights based on digital 989 reconstruction. Journal of Vertebrate Paleontology 34:1263-1291.

990 Lautenschlager S, Brassey C, Button D, Barrett P. 2016. Decoupled form and function in 991 disparate herbivorous dinosaur clades. Scientific Reports 6:26495. doi: 10.1038/srep26495.

992 Lautenschlager S, Gill P, Luo Z, Fagan M, Rayfield E. 2017. Morphological evolution of the 993 mammalian jaw adductor complex. Biological Reviews 92:1910-1940.

994 Lomax DR, Gibson BJA. 2015. The first definitive occurrence of Ichthyosaurus and

995 Temnodontosaurus (Reptilia: Ichthyosauria) in Nottinghamshire, England and a review of 996 ichthyosaur specimens from the county. Proceedings of the Geologists' Association 126:554997563.

998 Lomax DR, Massare JA. 2015. A new species of Ichthyosaurus from the Lower Jurassic of west 999 Dorset, England. Journal of Vertebrate Paleontology 35:e903260.

1000 Lomax DR, Massare JA. 2017. Two new species of Ichthyosaurus from the lowermost Jurassic 1001 (Hettangian) of Somerset, England. Papers in Palaeontology 3:1-20.

1002 Lomax DR, Massare JA. 2018. A second specimen of Protoichthyosaurus applebyi (Reptilia: 1003 Ichthyosauria) and additional information on the genus and species. Paludicola 11:164-178. 
1004 Lomax DR, Massare JA, Mistry R. 2017. The taxonomic utility of forefin morphology in Lower

1005 Jurassic ichthyosaurs: Protoichthyosaurus and Ichthyosaurus. Journal of Vertebrate

1006 Paleontology 37:e1361433.

1007 Lomax DR, Sachs S. 2017. On the largest Ichthyosaurus: A new specimen of Ichthyosaurus

1008 somersetensis containing an embryo. Acta Palaeontologica Polonica 62:575-584.

1009 Lomax DR, De La Salle P, Massare JA, Gallois R. 2018. A giant Late Triassic ichthyosaur from 1010 the UK and a reinterpretation of the Aust Cliff 'dinosaurian' bones. PLOS ONE 13:e0194742.

1011 Maisch MW, Hungerbühler A. 1997. Revision of Temnodontosaurus nuertingensis (v. Huene, 1012 1931), a large ichthyosaur from the Lower Pliensbachian (Lower Jurassic) of Nurtingen, South

1013 Western Germany. Stuttgarter Beiträge zur Naturkunde Serie B 248:1-11.

1014 Maisch MW. 2002. A braincase of Temnodontosaurus cf. trigonodon (von Theodori, 1843)

1015 (Ichthyosauria) from the Lower Jurassic of Germany. Geologica et Palaeontololgica 36:115-122.

1016 Marek R, Moon B, Williams M, Benton M. 2015. The skull and endocranium of a Lower

1017 Jurassic ichthyosaur based on digital reconstructions. Palaeontology 58:723-742.

1018 Martin JE, Frey E, Riess J. 1986. Soft-tissue preservation in ichthyosaurs and a stratigraphic

1019 review of the Lower Hettangian of Barrow-upon-Soar, Leicestershire. Transactions of the

1020 Leicestershire Literary \& Philosophical Society 80:58-72.

1021 Massare JA, Lomax DR. 2017. A taxonomic reassessment of Ichthyosaurus communis and I.

1022 intermedius and a revised diagnosis for the genus. Journal of Systematic Palaeontology 16:2631023277.

1024 McGowan C. 1973. The cranial morphology of the Lower Liassic latipinnate ichthyosaurs of

1025 England. Bulletin of the British Museum (Natural History) Geology 24: 1-109. 
1026 McGowan C. 1989. Computed tomography reveals further details of Excalibosaurus, a putative 1027 ancestor for the swordfish-like ichthyosaur Eurhinosaurus. Journal of Vertebrate Paleontology 1028 9:269-281.

1029 McGowan C. 1993. A new species of large, long-snouted ichthyosaur from the English lower 1030 Lias. Canadian Journal of Earth Sciences 30:1197-1204.

1031 McGowan C. 1996a. The taxonomic status of Leptopterygius Huene, 1922 (Reptilia:

1032 Ichthyosauria). Canadian Journal of Earth Sciences 33:439-443.

1033 McGowan C. 1996b. Giant ichthyosaurs of the Early Jurassic. Canadian Journal of Earth 1034 Sciences 33:1011-1021.

1035 McGowan C. 2003. A new specimen of Excalibosaurus from the English Lower Jurassic. 1036 Journal of Vertebrate Paleontology 23:950-956.

1037 McGowan C, Motani R. 2003. Handbook of Paleoherpetology, Part 8 Ichthyopterygia. Verlag 1038 Dr. Friedrich Pfeil pp. 175.

1039 Milner AC, Walsh S. 2010. Reptiles. In: Lord, A.R., Davis, P.G. (Eds.), Fossils from the Lower 1040 Lias of the Dorset Coast. The Palaeontological Association, pp. 372-394.

1041 Moon BC, Kirton AM. 2016. Ichthyosaurs of the British Middle and Upper Jurassic. Part 1 1042 Ophthalmosaurus. Monograph of the Palaeontographical Society 170:1-84.

1043 Motani R. 1999. On the evolution and homologies of ichthyopterygian forefins. Journal of 1044 Vertebrate Paleontology 19:28-41.

1045 Motani R. 2005. Evolution of fish-shaped reptiles (Reptilia: Ichthyopterygia) in their physical 1046 environments and constraints. Annual Review of Earth and Planetary Sciences, 33:395-420.

1047 Motani R. 2009. The evolution of marine reptiles. Evolution: Education and Outreach 2:2241048235. 
1049 Neenan J, Scheyer T. 2012. The braincase and inner ear of Placodus gigas (Sauropterygia,

1050 Placodontia) - a new reconstruction based on micro-computed tomographic data. Journal of

1051 Vertebrate Paleontology 32:1350-1357.

1052 Nicholls EL, Manabe M. 2004. Giant ichthyosaurs of the Triassic-A new species of

1053 Shonisaurus from the Pardonet Formation (Norian: Late Triassic) of British Columbia. Journal

1054 of Vertebrate Paleontology 24:838-849.

1055 Porro L, Rayfield, E, Clack J. 2015a. Descriptive anatomy and three-dimensional reconstruction

1056 of the skull of the early tetrapod Acanthostega gunnari Jarvik, 1952. PLOS ONE 10:e0118882.

1057 doi: 10.1371/journal.pone.0118882.

1058 Porro L, Rayfield E, Clack J. 2015b. Computed tomography, anatomical description and three-

1059 dimensional reconstruction of the lower jaw of Eusthenopteron foordi Whiteaves, 1881 from the 1060 Upper Devonian of Canada. Palaeontology 58:1031-1047.

1061 Porro L, Witmer L, Barrett P. 2015c. Digital preparation and osteology of the skull of

1062 Lesothosaurus diagnosticus (Ornithischia: Dinosauria). PeerJ 3:e1494. doi: 10.7717/peerj.1494.

1063 Quenstedt FA. 1858. Der Jura. Tübingen pp. 842.

1064 Radley JD. 2003. Warwickshire's Jurassic geology: past, present and future. Mercian Geologist

1065 15:209-218.

1066 Rayfield E, Norman D, Horner C, Horner J, Smith P, Thomason J, Upchurch P. 2001. Cranial

1067 design and function in a large theropod dinosaur. Nature 409:1033-1037.

1068 Sato T, Wu X, Tirabasso A, Bloskie P. 2011. Braincase of a polycotylid plesiosaur (Reptilia:

1069 Sauropterygia) from the Upper Cretaceous of Manitoba, Canada. Journal of Vertebrate

1070 Paleontology 31:313-329. 
1071 Seeley HG. 1874. On the pectoral arch and forelimb of Ophthalmosaurus, a new ichthyosaurian 1072 genus from the Oxford Clay. Quarterly Journal of the Geological Society of London 30:696-707.

1073 Sharp A. 2014. Three dimensional digital reconstruction of the jaw adductor musculature of the 1074 extinct marsupial giant Diprotodon optatum. PeerJ 2:e514. doi: 10.7717/peerj.514.

1075 Smith AS, Radley JD. 2007. A marine reptile fauna from the Early Jurassic Saltford Shale (Blue 1076 Lias Formation) of central England. Proceedings of the Yorkshire Geological Society 56:2531077260.

1078 Sollas WJ. 1916. The skull of Ichthyosaurus, studied in serial sections. Philosophical 1079 Transactions of the Royal Society of London, Series B 208:63-126.

1080 VanBuren CS, Evans DC. 2017. Evolution and function of anterior cervical vertebral fusion in 1081 tetrapods. Biological Reviews 92:608-626.

1082 Wade M. 1990. A review of the Australian Cretaceous longipinnate ichthyosaur Platypterygius 1083 (Ichthyosauria: Ichthyopterygia). Memoirs of the Queensland Museum 28: 115-137

1084 Williams M, Benton MJ, Ross A. 2015. The Strawberry Bank Lagerstätte reveals insights into 1085 Early Jurassic life. Journal of the Geological Society 172:683-692.

1086 Witmer LM. 1997. The evolution of the antorbital cavity of archosaurs: a study in soft-tissue 1087 reconstruction in the fossil record with an analysis of the function of pneumaticity. Society of 1088 Vertebrate Paleontology Memoir 3:1-73.

1089 Wroe S. 2007. Cranial mechanics compared in extinct marsupial and extant African lions using a 1090 finite-element approach. Journal of Zoology 4:332-339.

1091 Young M, Bird J. 1828. A geological survey of the Yorkshire Coast: describing the strata and 1092 fossils occurring between the Humber and the Tees, from the German ocean to the plain of York. 1093 Whitby 368 pp. 


\section{Figures}

1096

1097 Figure 1. Three-dimensional skull of BMT 1955.G35.1, Protoichthyosaurus prostaxalis. A, 1098 original photograph of the first skull reconstruction (left lateral view) within a couple of years of 1099 the 1955 excavation. Note that the prefrontal and postorbital are present, which we have been 1100 unable to locate in our study. B, skull in left lateral view, as reconstructed in 2015. C, skull in 1101 right lateral view, as reconstructed in 2015. Note the distinctive asymmetric maxilla with long, 1102 narrow anterior process. Teeth are not in their original positions. Scale bar represents $20 \mathrm{~cm}$.

Figure 2. Surface models (generated from CT scan data) of preserved bones from the upper jaw of BMT 1955.G35.1, Protoichthyosaurus prostaxalis. Right (A) and left (B) lateral views of the cranium. Medial views of the right (C) and left (D) sides of the cranium. Dorsal (E) and ventral (F) views of the cranium. Lateral views of the right $(\mathrm{G})$ and left $(\mathrm{H})$ premaxillae. Dorsal views of the right (I) and left $(\mathrm{J})$ premaxillae. Posterior $(\mathrm{K})$ view of the upper jaw. Individual bones are shown in different colors. Bones in $\mathrm{G}-\mathrm{J}$ are transparent to visualize internal canals (shown in red opaque). Teeth are not in their original positions. Abbreviations: bs, basioccipital; ex, exoccipital; f?, possible fragment of frontal; j, jugal; 1, lacrimal; mx, maxilla; n, nasal; p, parietal;

1112 pf, prefrontal; pmx, premaxilla; pt, pterygoid; q, quadrate; so, supraoccipital; sp, supratemporal; st, stapes. Scale bars equal $10 \mathrm{~cm}$.

1115 Figure 3. Surface models (generated from micro-CT scan data) of preserved palatal and 1116 braincase bones from BMT 1955.G35.1, Protoichthyosaurus prostaxalis. Right medial (A) and 
1117 left lateral (B) views, dorsal (C) and ventral (D) views, and anterior (E) and posterior (F) views.

1118 Isolated supraoccipital in right anterolateral view (G). Individual bones are shown in different

1119 colors. Supraoccipital in G is transparent to visualize internal canals (shown in red opaque).

1120 Abbreviations: bs, basioccipital; ex, exoccipital; f?, probable fragment of upper pterygoid wing;

1121 p, parietal; pt, pterygoid; q, quadrate; se, sella turcica; so, supraoccipital; sp, supratemporal; st, 1122 stapes. Scale bars equal $10 \mathrm{~cm}$, except for $(\mathrm{G})$ which equals $5 \mathrm{~cm}$.

1123

1124 Figure 4. Surface models (generated from CT scan data) of preserved bones from the lower jaw 1125 of BMT 1955.G35.1, Protoichthyosaurus prostaxalis. Lateral views of the right (A) and left (B) lower jaws. Medial views of the right (C) and left (D) lower jaws. Dorsal (E) and ventral (F) views of the both halves of the lower jaws. Lateral views of the right $(\mathrm{G})$ and left $(\mathrm{H})$ dentary. Ventral views of the right (I) and left (J) dentaries. Lateral oblique (K) view of the left surangular. Individual bones are shown in different colors. Bones in $\mathrm{G}-\mathrm{K}$ are transparent to visualize internal canals (shown in red opaque). Teeth are not in their original positions. Abbreviations: an, angular; ar, articular, d, dentary; f?, possible surangular fragment; sa, surangular; sp, splenial; spf, splenial fragment. Scale bars equal $10 \mathrm{~cm}$.

Figure 5. Elements of the skull, palate, lower jaw and dentition of BMT 1955.G35.1, (A), ventral (B), posterior (C) and anterior (D) view. E-F, incomplete and damaged left pterygoid in posterior (E) and ventral (F) view. Note the three wing-like projections in posterior view. G-I, 1138 incomplete and damaged left quadrate in anterior $(\mathrm{G})$, posterior $(\mathrm{H})$ and lateral (I) view. J, hyoids 1139 in dorsal view. K-L, incomplete and damaged right nasal in dorsal (K) and (L) lateral view. M, 
1140 incomplete and damaged right postfrontal in dorsal view. N, practically complete tooth missing

1141 the tip of the crown. Note that the root is large with prominent grooves that extend to the base of

1142 the crown and continue as longitudinal striations on the crown. Abbreviations: ac, articular

1143 condyle; (?)ce, impression of cerebellum; ch, impression of cerebral hemisphere; dpf, descending

1144 parietal flange; eed, extra-encephalic depression; ocl, occipital lamella; ol, impression of optic

1145 lobe; op, elongate openings in the posterior surface of the parietal; par, palatal ramus; ps, parietal

1146 shelf (ridge); qf, quadratojugal facet; sc, sagittal crest; spt, supratemporal probably fused with

1147 parietals; vs, ventral surface. Scale bars represent $3 \mathrm{~cm}$.

1148

1149 Figure 6. Braincase elements of BMT 1955.G35.1, Protoichthyosaurus prostaxalis. A-C,

1150 incomplete supraoccipital in posterior (A), dorsal (B) and ventral (C) view. D-E,

1151 parabasisphenoid with complete basisphenoid and broken parasphenoid in anterior (D) and

1152 ventral (E) view. F-G, left opisthotic in anteromedial (F) and ventrolateral (G) view. Note the 'V-

1153 shaped' membranous impression in F. H, incomplete left stapes in posterior view. Abbreviations:

1154 bf, facet for basipterygoid facet; bof, basioccipital facet; bp, basipterygoid process; cf, carotid

1155 foramen; ds, dorsum sellae; ef, exoccipital facet; hsc, horizontal semicircular canal; (?)ma,

1156 muscle attachment; mh, medial head; mr, median ridge; $\mathrm{p}$, base of parasphenoid; pp, paroccipital

1157 process; pvsc, posterior vertical semicircular canal; rfm, roof of foramen magnum; sac, sacculus;

1158 sf, stapedial facet; st, sella turcica; t, paired trabeculae; tg, trenchant groove; (?)ut, utriculus.

1159 Scale bars represent $3 \mathrm{~cm}$.

1160

1161 Figure 7. Elements of the postcranial skeleton of BMT 1955.G35.1, Protoichthyosaurus

1162 prostaxalis. A-B, probable 'unfused' (see text for details) axis vertebra in anterior (A) and 
1163 ventral (B) view. Note the unusual, almost rugose anterior surface. The dark, circular element to

1164 the right is a poorly preserved bivalve mollusk. C, left coracoid in dorsal view. D, incomplete left

1165 scapula in lateral view. E-F, left humerus in dorsal (E) and ventral (F) view. Note that the dorsal

1166 process (trochanter dorsalis) is damaged, as is the facet for the ulna. G, complete ilium in either

1167 lateral or medial view. Note that the posterior end (to the right) is bulbous, relative to the shaft.

1168 H-I, damaged (?)right femur in dorsal (H) and ventral (view). Abbreviations: af, anterior facet;

1169 aif, facet for the axial intercentrum; an, anterior notch; bpe, broken posterior end; bpe, bulbous

1170 posterior end; ccf, facet for the cervical centrum; dp, dorsal process; dpc, deltopectoral crest; ff,

1171 fibular facet; gf, glenoid facet; if, intercoracoid facet; pm?, predation marks; pn, posterior notch;

1172 rf, radial facet; sf, scapular facet; tf, tibial facet; uf, ulnar facet; vp, ventral process. Scale bars

1173 represent $3 \mathrm{~cm}$.

1174

1175 Figure 8. Surface models (generated from CT scan data) of the reassembled skull of BMT 1176 1955.G35.1, Protoichthyosaurus prostaxalis, highlighting differences between fossil bone 1177 (grey), regions reconstructed during original reassembly in the 1950s (yellow), and regions 1178 reconstructed in the course of the current work (blue). Right (A) and left (B) lateral, and dorsal 1179 (C) and ventral (D) views of the upper and lower jaws.

Figure 9. Surface models (generated from CT scan data) of the skull of BMT 1955.G35.1,

1182 Protoichthyosaurus prostaxalis, after the removal of minor damage and duplication/mirroring of 1183 asymmetrically preserved elements, and digital articulation of individual bones to produce a 1184 more accurate digital 3D reconstruction. Displacement of the lower jaw and premaxillae and 1185 nasals are the result of deformation (see text). Left lateral (A), dorsal (B), ventral (C), anterior 
1186 (D), and posterior (E) views of the upper and lower jaws. Individual bones labelled using the 1187 same colors as Figures 2-4.

1188 


\section{Figure 1}

Three-dimensional skull of BMT 1955.G35.1, Protoichthyosaurus prostaxalis.

A, original photograph of the first skull reconstruction (left lateral view) within a couple of years of the 1955 excavation. Note that the prefrontal and postorbital are present, which we have been unable to locate in our study. B, skull in left lateral view, as reconstructed in 2015. C, skull in right lateral view, as reconstructed in 2015. Note the distinctive asymmetric maxilla with long, narrow anterior process. Teeth are not in their original positions. Scale bar represents $20 \mathrm{~cm}$. 


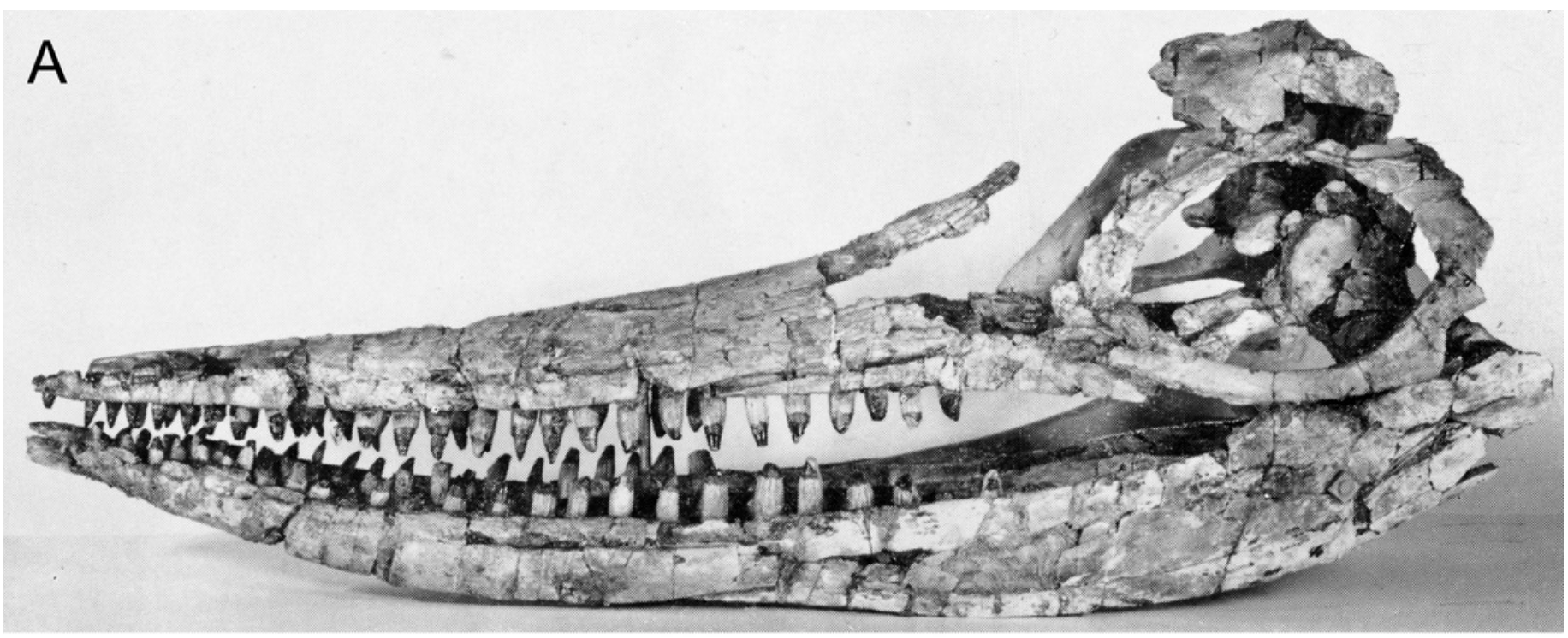

B

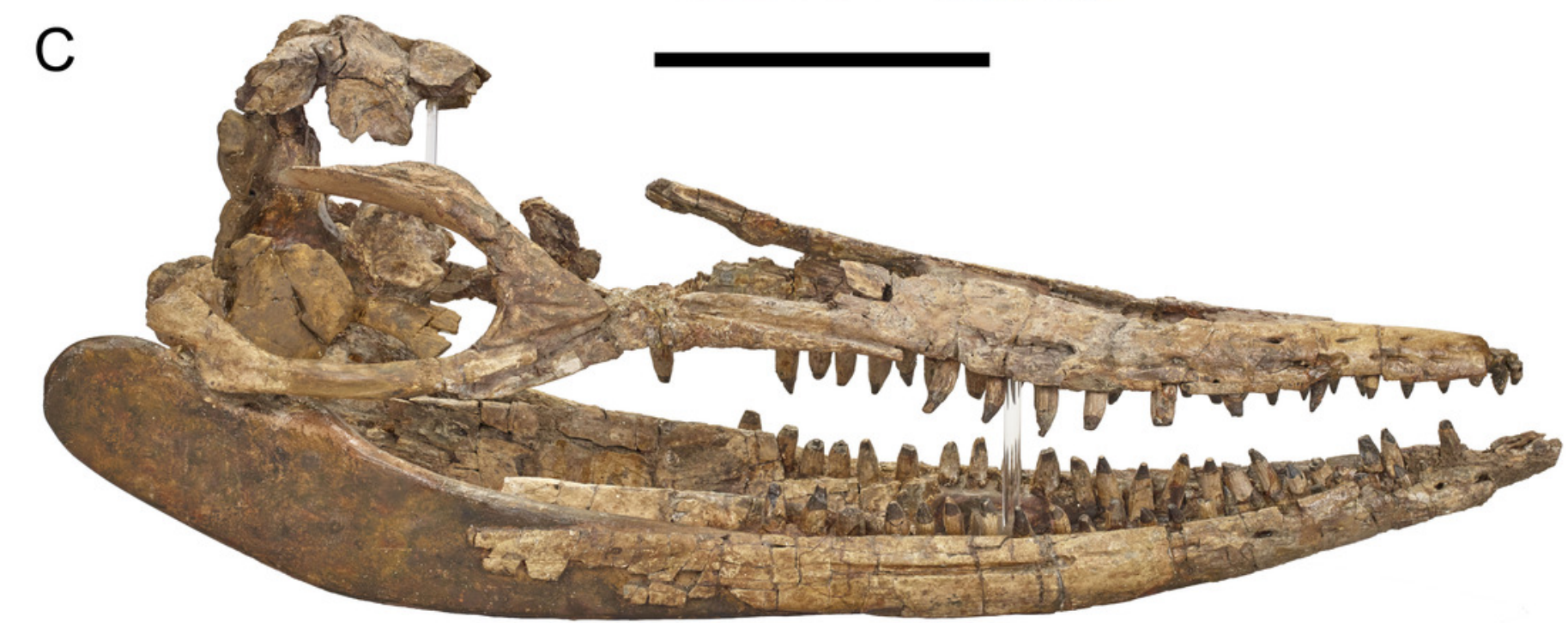




\section{Figure 2}

Surface models (generated from CT scan data) of preserved bones from the upper jaw of BMT 1955.G35.1, Protoichthyosaurus prostaxalis.

Right (A) and left (B) lateral views of the cranium. Medial views of the right (C) and left (D) sides of the cranium. Dorsal (E) and ventral (F) views of the cranium. Lateral views of the right $(\mathrm{G})$ and left $(\mathrm{H})$ premaxillae. Dorsal views of the right (I) and left (J) premaxillae. Posterior (K) view of the upper jaw. Individual bones are shown in different colors. Bones in G-J are transparent to visualize internal canals (shown in red opaque). Teeth are not in their original positions. Abbreviations: bs, basioccipital; ex, exoccipital; f?, possible fragment of frontal; j, jugal; I, lacrimal; mx, maxilla; n, nasal; p, parietal; pf, prefrontal; pmx, premaxilla; pt, pterygoid; q, quadrate; so, supraoccipital; sp, supratemporal; st, stapes. Scale bars equal $10 \mathrm{~cm}$. 


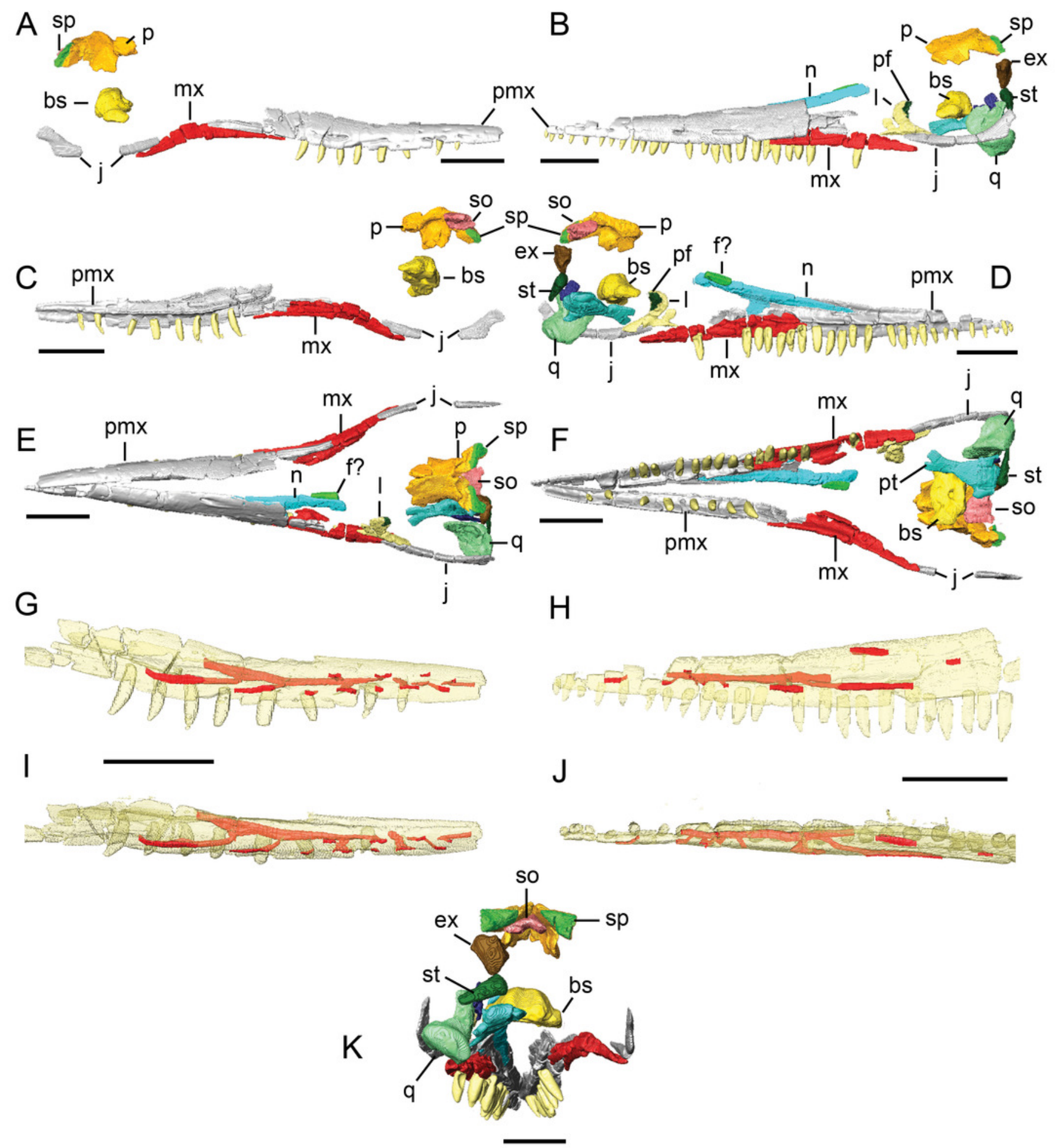




\section{Figure 3}

Surface models (generated from micro-CT scan data) of preserved palatal and braincase bones from BMT 1955.G35.1, Protoichthyosaurus prostaxalis.

Right medial (A) and left lateral (B) views, dorsal (C) and ventral (D) views, and anterior (E) and posterior (F) views. Isolated supraoccipital in right anterolateral view (G). Individual bones are shown in different colours. Supraoccipital in $\mathrm{G}$ is transparent to visualize internal canals (shown in red opaque). Abbreviations: bs, basioccipital; ex, exoccipital; f?, probable fragment of upper pterygoid wing; p, parietal; pt, pterygoid; q, quadrate; se, sella turcica; so, supraoccipital; sp, supratemporal; st, stapes. Scale bars equal $10 \mathrm{~cm}$, except for (G) which equals $5 \mathrm{~cm}$. 

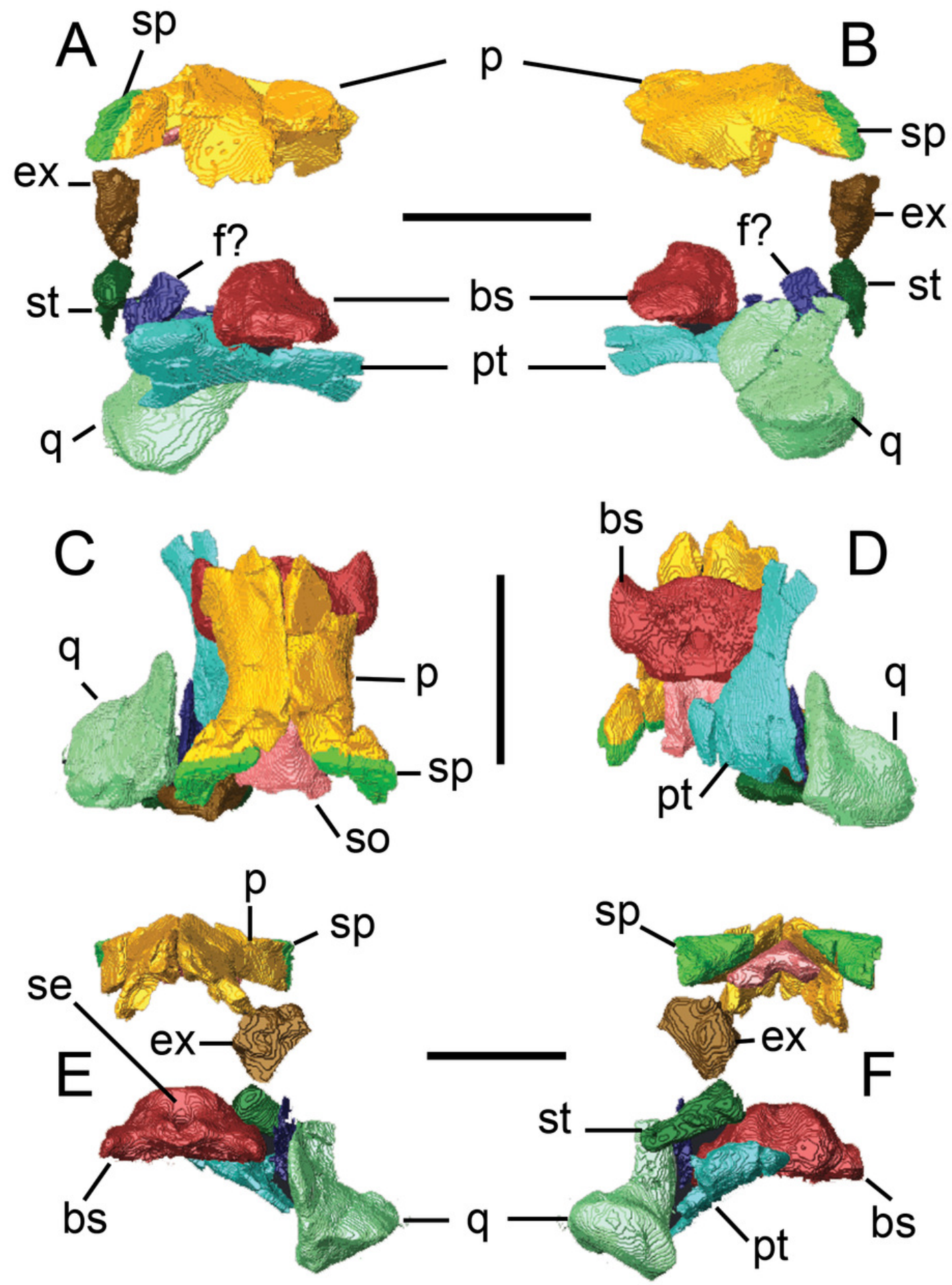


\section{Figure 4}

Surface models (generated from CT scan data) of preserved bones from the lower jaw of BMT 1955.G35.1, Protoichthyosaurus prostaxalis.

Lateral views of the right (A) and left (B) lower jaws. Medial views of the right (C) and left (D) lower jaws. Dorsal $(E)$ and ventral $(F)$ views of the both halves of the lower jaws. Lateral views of the right $(\mathrm{G})$ and left $(\mathrm{H})$ dentary. Ventral views of the right (I) and left (J) dentaries. Lateral oblique $(K)$ view of the left surangular. Individual bones are shown in different colors. Bones in G-K are transparent to visualize internal canals (shown in red opaque). Teeth are not in their original positions. Abbreviations: an, angular; ar, articular, $d$, dentary; f?, possible surangular fragment; sa, surangular; sp, splenial; spf, splenial fragment. Scale bars equal 10 $\mathrm{cm}$. 


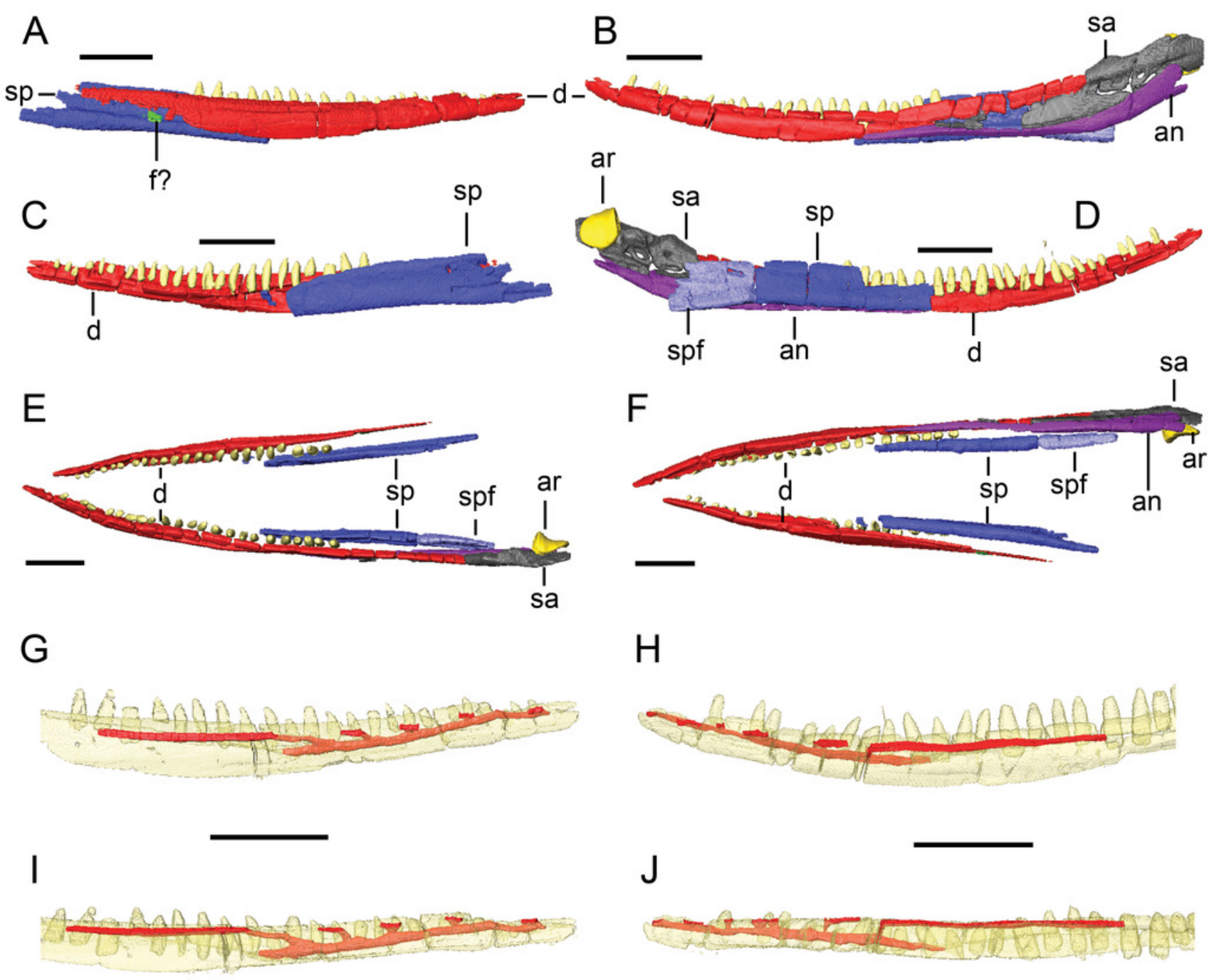




\section{Figure 5}

Elements of the skull, palate, lower jaw and dentition of BMT 1955.G35.1, Protoichthyosaurus prostaxalis.

A-D, incomplete and damaged, articulated parietals in dorsal (A), ventral (B), posterior (C) and anterior (D) view. E-F, incomplete and damaged left pterygoid in posterior (E) and ventral $(F)$ view. Note the three wing-like projections in posterior view. G-I, incomplete and damaged left quadrate in anterior (G), posterior (H) and lateral (I) view. J, hyoids in dorsal view. $\mathrm{K}-\mathrm{L}$, incomplete and damaged right nasal in dorsal (K) and (L) lateral view. $\mathrm{M}$, incomplete and damaged right postfrontal in dorsal view. N, practically complete tooth missing the tip of the crown. Note that the root is large with prominent grooves that extend to the base of the crown and continue as longitudinal striations on the crown. Abbreviations: ac, articular condyle; (?)ce, impression of cerebellum; ch, impression of cerebral hemisphere; dpf, descending parietal flange; eed, extra-encephalic depression; ocl, occipital lamella; ol, impression of optic lobe; op, elongate openings in the posterior surface of the parietal; par, palatal ramus; ps, parietal shelf (ridge); qf, quadratojugal facet; sc, sagittal crest; spt, supratemporal probably fused with parietals; vs, ventral surface. Scale bars represent $3 \mathrm{~cm}$. 

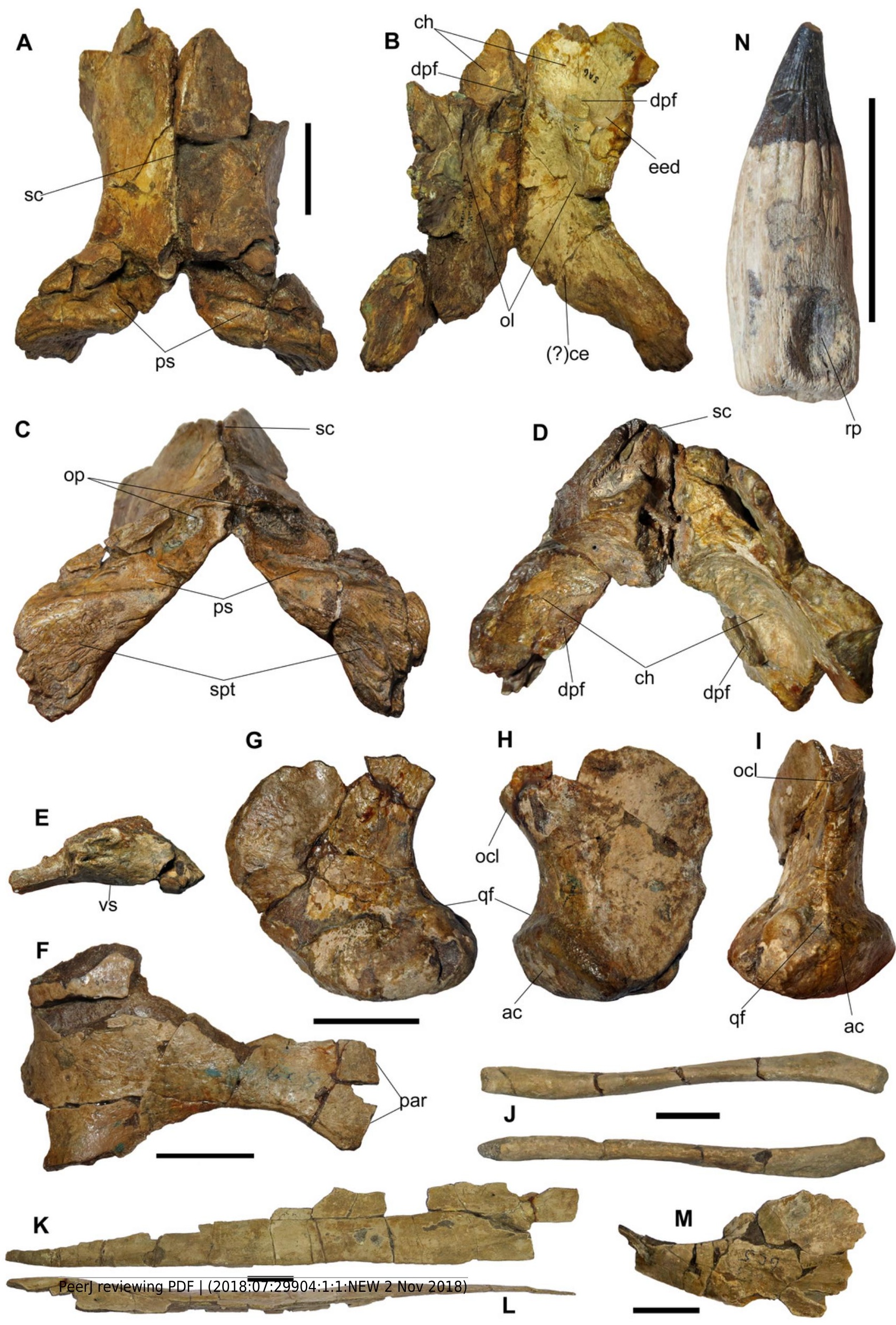


\section{Figure 6}

Braincase elements of BMT 1955.G35.1, Protoichthyosaurus prostaxalis.

A-C, incomplete supraoccipital in posterior (A), dorsal (B) and ventral (C) view. D-E, parabasisphenoid with complete basisphenoid and broken parasphenoid in anterior (D) and ventral (E) view. F-G, left opisthotic in anteromedial $(F)$ and ventrolateral $(G)$ view. Note the ' $\mathrm{V}$-shaped' membranous impression in $\mathrm{F}$. $\mathrm{H}$, incomplete left stapes in posterior view. Abbreviations: bf, facet for basipterygoid facet; bof, basioccipital facet; bp, basipterygoid process; cf, carotid foramen; ds, dorsum sellae; ef, exoccipital facet; hsc, horizontal semicircular canal; (?)ma, muscle attachment; mh, medial head; mr, median ridge; $\mathrm{p}$, base of parasphenoid; pp, paroccipital process; pvsc, posterior vertical semicircular canal; rfm, roof of foramen magnum; sac, sacculus; sf, stapedial facet; st, sella turcica; t, paired trabeculae; $\mathrm{tg}$, trenchant groove; (?)ut, utriculus. Scale bars represent $3 \mathrm{~cm}$. 


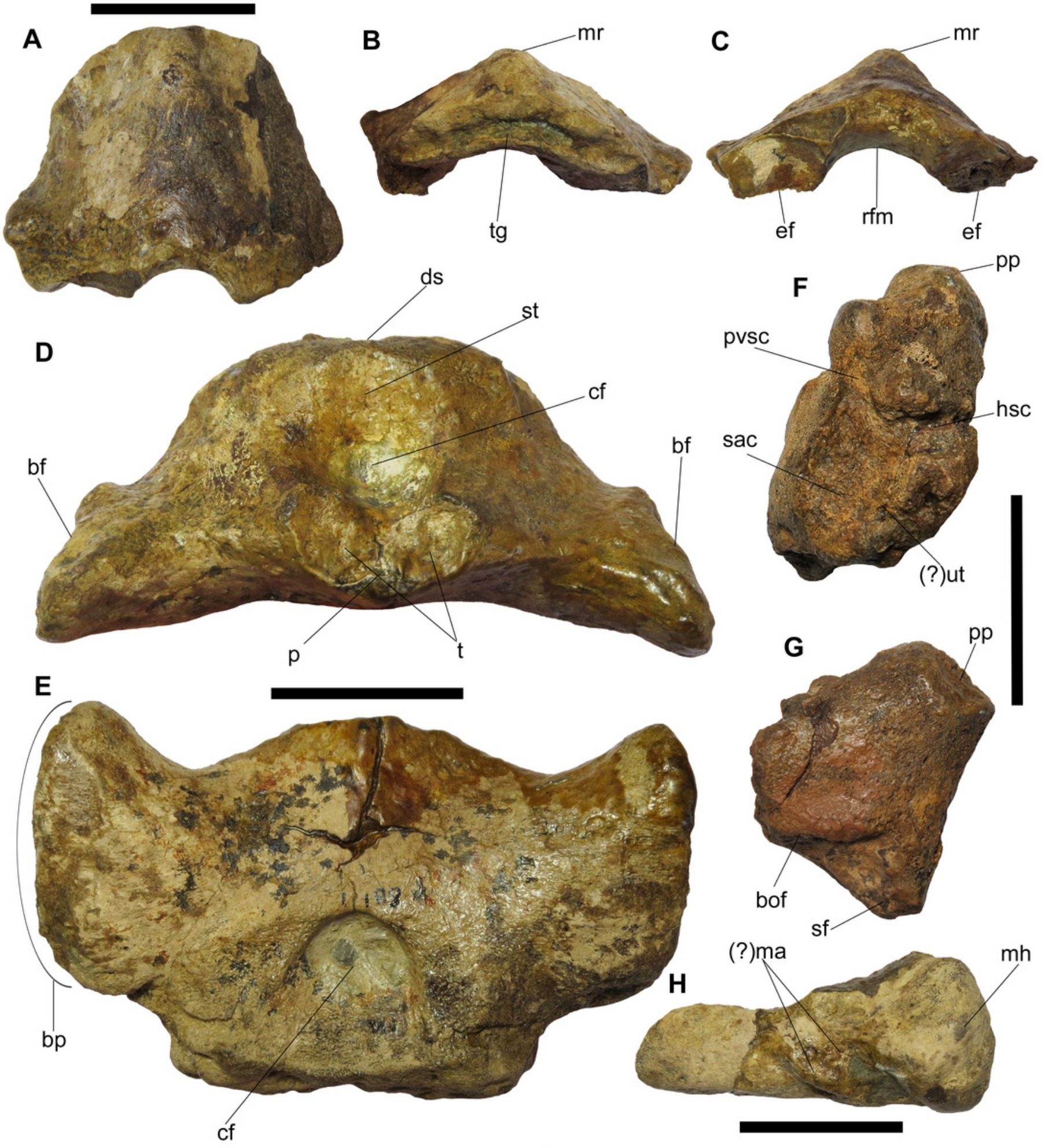




\section{Figure 7}

Elements of the postcranial skeleton of BMT 1955.G35.1, Protoichthyosaurus prostaxalis.

A-B, probable 'unfused' (see text for details) axis vertebra in anterior (A) and ventral (B) view. Note the unusual, almost rugose anterior surface rarely seen in ichthyosaurs. The dark, circular element to the right is a poorly preserved bivalve mollusc. C, left coracoid in dorsal view. D, incomplete left scapula in lateral view. E-F, left humerus in dorsal (E) and ventral (F) view. Note that the dorsal process (trochanter dorsalis) is damaged, as is the facet for the ulna. G, complete ilium in either lateral or medial view. Note that the posterior end (to the right) is bulbous, relative to the shaft. $\mathrm{H}-\mathrm{I}$, damaged (?)right femur in dorsal $(\mathrm{H})$ and ventral (view). Abbreviations: af, anterior facet; aif, facet for the axial intercentrum; an, anterior notch; bpe, broken posterior end; bpe, bulbous posterior end; ccf, facet for the cervical centrum; dp, dorsal process; dpc, deltopectoral crest; ff, fibular facet; gf, glenoid facet; if, intercoracoid facet; pm?, predation marks; pn, posterior notch; rf, radial facet; sf, scapular facet; tf, tibial facet; uf, ulnar facet; vp, ventral process. Scale bars represent $3 \mathrm{~cm}$. 


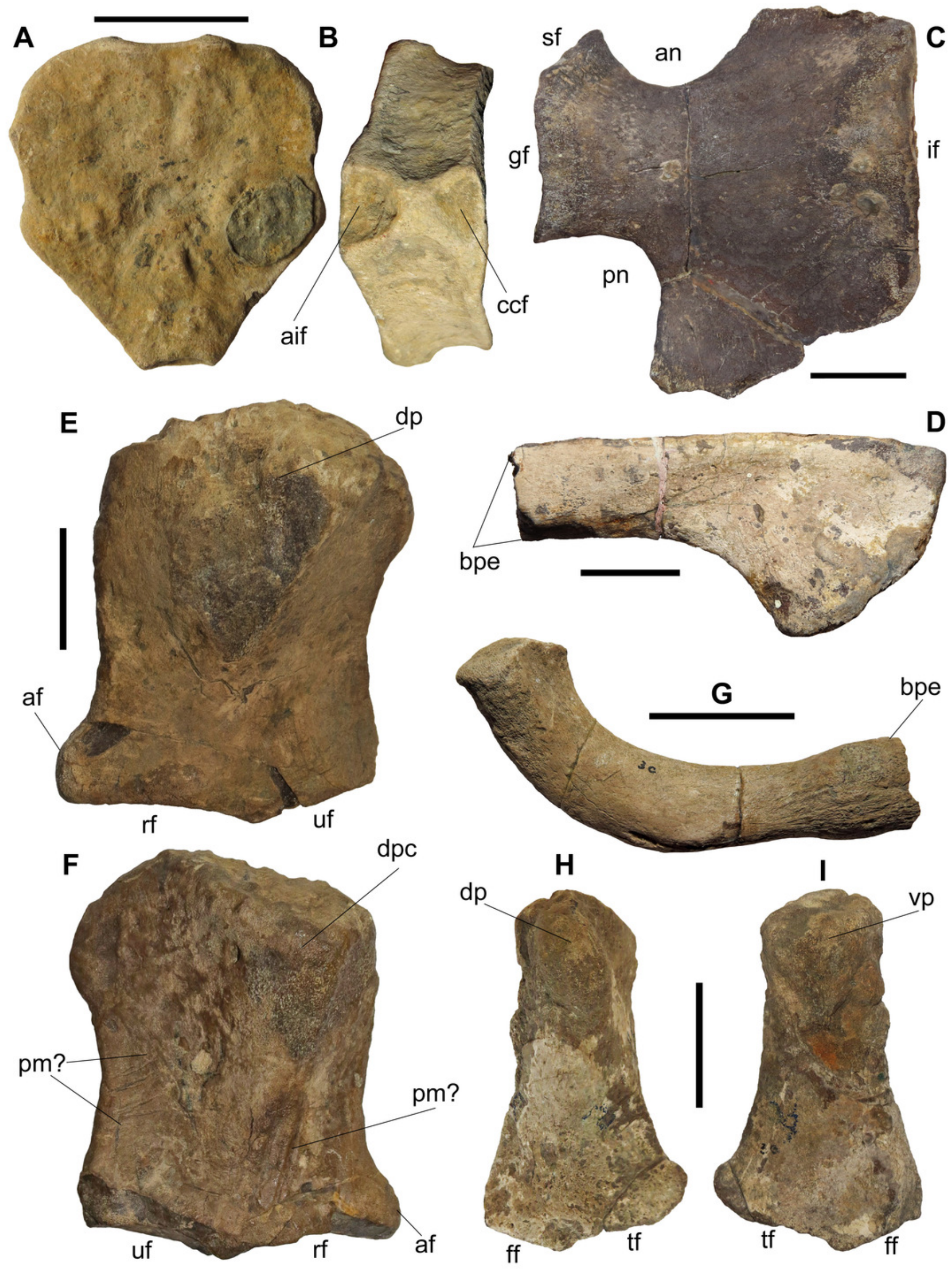


Figure 8

Surface models (generated from CT scan data) of the skull of BMT 1955.G35.1, Protoichthyosaurus prostaxalis, highlighting differences between the original skull and reconstruction.

Fossil bone (grey), regions reconstructed during original reassembly in the 1950s (yellow), and regions reconstructed in the course of the current work (blue). Right (A) and left (B) lateral, and dorsal (C) and ventral (D) views of the upper and lower jaws.

A

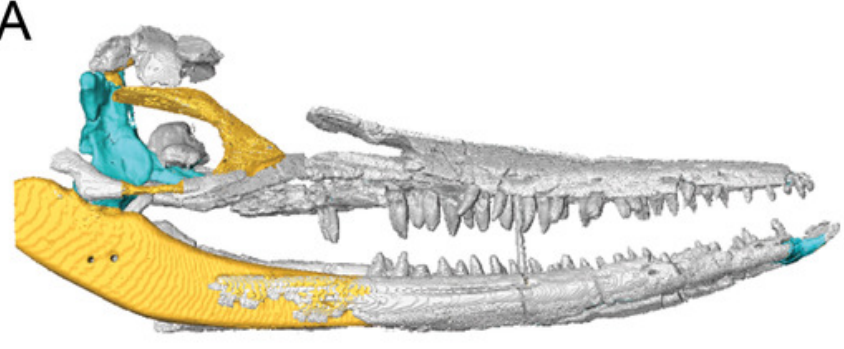

C

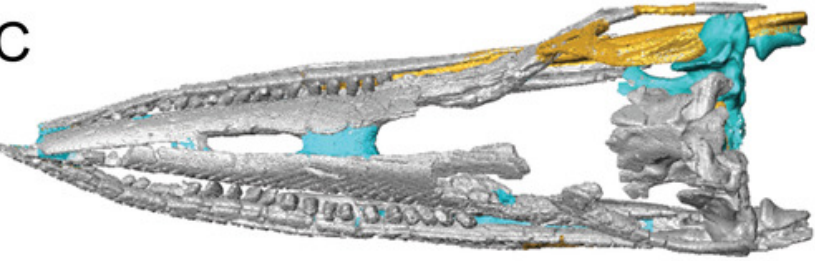

B

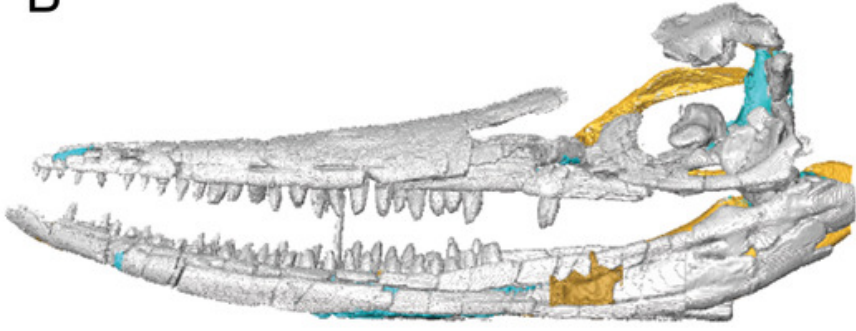

D

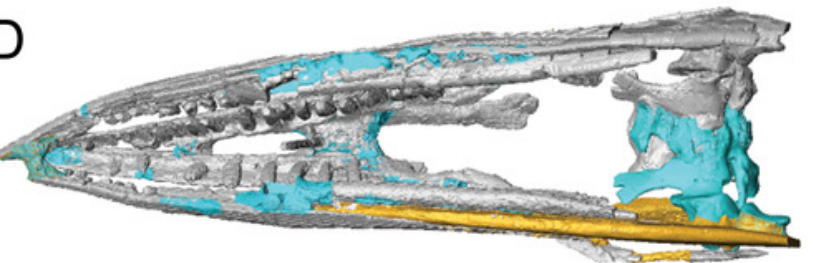




\section{Figure 9}

Surface models (generated from CT scan data) of the skull of BMT 1955.G35.1, Protoichthyosaurus prostaxalis.

After the removal of minor damage and duplication/mirroring of asymmetrically preserved elements, and digital articulation of individual bones to produce a more accurate digital 3D reconstruction. Displacement of the lower jaw and premaxillae and nasals are the result of deformation (see text). Left lateral (A), dorsal (B), ventral (C), anterior (D), and posterior (E) views of the upper and lower jaws. Individual bones labeled using the same colors as Figures 2-4.

A

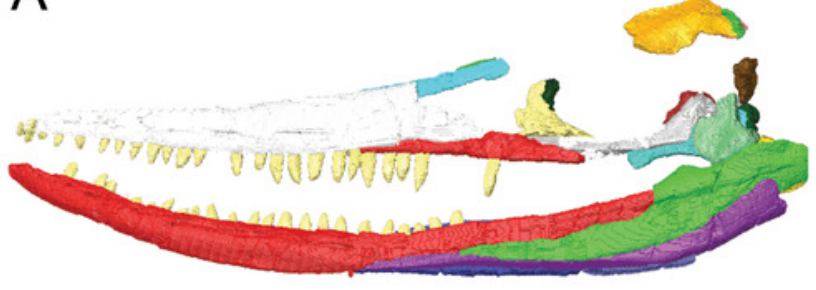

C

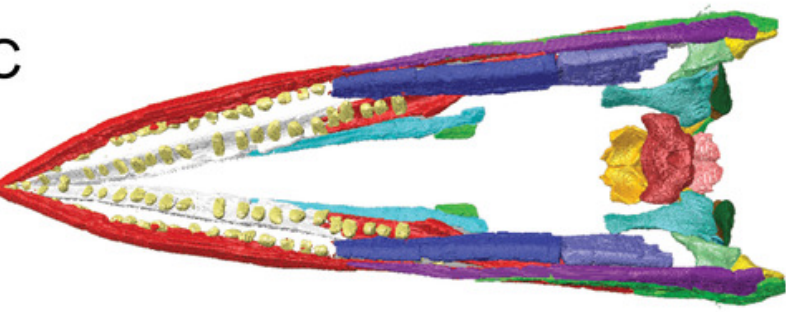

B
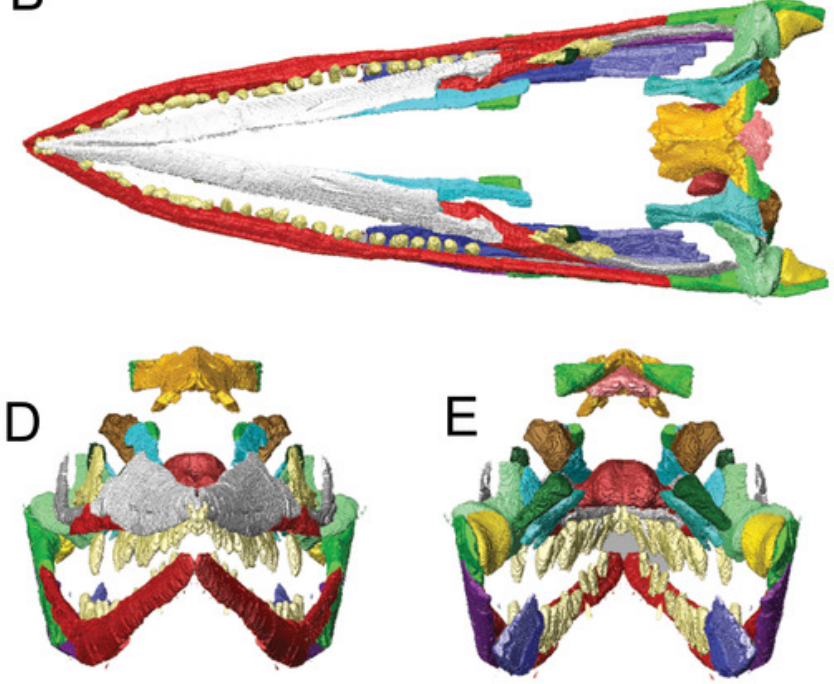


\section{Table $\mathbf{1}$ (on next page)}

Measurements of some skull and postcranial elements of BMT 1955.G35.1, Protoichthyosaurus prostaxalis.

'Width' for fin elements refers to the anteroposterior dimension, perpendicular to the long axis of the fin. $L$ and $R$ denote measurement of left or right elements. Asterisk denotes an estimate because the bone is damaged or elements are missing. 


\section{Table 1}

2 Measurements of some skull and postcranial elements of BMT 1955.G35.1, Protoichthyosaurus

3 prostaxalis. 'Width' for fin elements refers to the anteroposterior dimension, perpendicular to the

4 long axis of the fin. $\mathrm{L}$ and $\mathrm{R}$ denote measurement of left or right elements. Asterisk denotes an

5 estimate because the bone is damaged or elements are missing.

6

\begin{tabular}{lc} 
Element & (cm) \\
\hline Skull length & $80^{*}$ \\
Maxilla length & $25.5 \mathrm{R} 24.2 \mathrm{~L}^{*}$ \\
Lower jaw length & $87^{*}$ \\
Basisphenoid length & 5.82 \\
Basisphenoid width & 9.95 \\
Supraoccipital height & 5.04 \\
Supraoccipital width & 6.11 \\
Quadrate length & 9.4 \\
Quadrate max width & 8.2 \\
Hyoid length & $18.5 \mathrm{R} 18.2 \mathrm{~L}$ \\
Coracoid med-lat length & 12.16 \\
Coracoid ant-post & 13.66 \\
Scapula preserved length & $12.9^{*}$ \\
Scapula proximal end only & 7.25 \\
Humerus length & 10.4 \\
Humerus distal width & $8.59^{*}$ \\
Humerus proximal width & 7.66 \\
Femur length & 8.7 \\
Femur distal width & 5.1 \\
Femur proximal width & $2.5^{*}$ \\
Ilium length & 9.38 \\
Humerus/Femur ratio & 1.2 \\
\hline
\end{tabular}

7

8 